\title{
Structure, function, and biology of SHIP proteins
}

\author{
Larry R. Rohrschneider, ${ }^{1}$ John F. Fuller, Ingrid Wolf, Yan Liu, and David M. Lucas ${ }^{2}$ \\ Fred Hutchinson Cancer Research Center, Division of Basic Sciences, Seattle, Washington 98109-1024 USA
}

One of the "simple" curiosities of life, at least for a biological scientist, is how the growth and development of a complete organism from a single cell is controlled. Part of the answer includes growth factor receptors and their respective ligands, which transduce signals across cell membranes and into the nucleus for transcriptional readout. The molecular nature of these intracellular signals determines the type of signals, the pathways involved, subsequent regulatory interactions, and eventual transcription factor activation/repression. Hematopoietic cell development has been a fruitful system for the analysis of these signals because mature blood cells develop from a small population of self-replicating stem cells in the bone marrow, providing a convenient model cell system to study these mechanisms. In recent years a new signaling protein component of many growth factor receptor signaling pathways has been identified, called SHIP (브2-containing Inositol 5'-Phosphatase). This review presents current structural information on the SHIP protein and its various roles in cellular regulation.

SHIP was initially observed as a tyrosine-phosphorylated protein after stimulation of blood cells by any of a broad number of cytokines and growth factors (Damen et al. 1993; Kavanaugh and Williams 1994; Lioubin et al. 1994; Liu et al. 1994; Matsuguchi et al. 1994; Saxton et al. 1994; Drachman et al. 1995; Chacko et al. 1996; Crowley et al. 1996). cDNAs for the cognate protein were cloned by several laboratories. The cloning methods varied, and some utilized the biochemically identified interactions of SHIP with Grb2, Shc, or Fc receptors to isolate a $\sim 145-\mathrm{kD}$ protein, obtain peptide sequences, and screen a cDNA library with degenerate probes (Damen et al. 1996; Kavanaugh et al. 1996; Ono et al. 1996; Odai et al. 1997). A novel approach employing a modified yeast two-hybrid screen was used in two cases in which the yeast expressed an exogenous tyrosine kinase. This allowed identification of tyrosine-phosphorylated SHIP cDNA segments by specific interactions with the PTB domain of She (Lioubin et al. 1996) or the cytoplasmic sequence of an Fc receptor (Osborne et al. 1996).

${ }^{1}$ Corresponding author.

E-MAIL lrohrsch@fhcrc.org; FAX (206) 667-3308.

${ }^{2}$ Present address: Department of Internal Medicine, Ohio State University, Columbus, Ohio 43210 USA.
Other cloning methods obtained SHIP cDNA from EST probes (Q. Liu et al. 1997) or by general cloning of inositol 5'-phosphatases using degenerate PCR (Drayer et al. 1996). Subsequent studies have begun to examine the in vivo biological function of SHIP, and the following sections will cover sequential details on the structure and biological function with a critical analysis of the overall role of SHIP in cellular regulation.

\section{SHIP structure and protein interaction motifs}

\section{SHIP structure}

The domain and motif structure of p145 SHIP is shown in Figure 1. SHIP contains 1190 amino acids, with a calculated molecular mass of $133 \mathrm{kD}$, and contains several identifiable motifs important for protein-protein interactions. The amino-terminal Src homology 2 (SH2) domain (Schaffhausen 1995) was an early identifying characteristic of SHIP and is vital in the interactions of SHIP with a large number of intracellular signaling proteins. As will be discussed below, the numerous SH2-mediated interactions of SHIP are currently being exploited to investigate its function. The central 400-500 amino acid portion of SHIP encodes an enzymatic activity for removal of phosphate from the $5^{\prime}$ position of inositol polyphosphate, and $\sim 300$ amino acids of undefined function separate the SH2 domain from the $5^{\prime}$-phosphatase domain. About 350 amino acids comprise a distinct carboxy-terminal domain, which encodes two NPXY motifs (in single-letter amino acid designation). Upon tyrosine phosphorylation of this motif, proteins containing a phosphotyrosine binding (PTB) domain (van der Geer and Pawson 1995) are known to interact with SHIP at these sites. For example, the PTB domain of Shc is known to bind to both these sites in phosphorylated SHIP (Lioubin et al. 1996; Lamkin et al. 1997). Phosphorylation of the NPXY motifs may also serve as potential interaction sites for SH2 domain-containing proteins, depending on the three amino acids adjacent to the carboxyl side of the tyrosine. Finally, several PxxP motifs are present within the carboxyl terminus and may serve as binding sites for proteins containing SH3 domains. The potential PxxP motifs are shown within the carboxy-terminal domain of SHIP in Figure 1, with the broader dark green bands as 

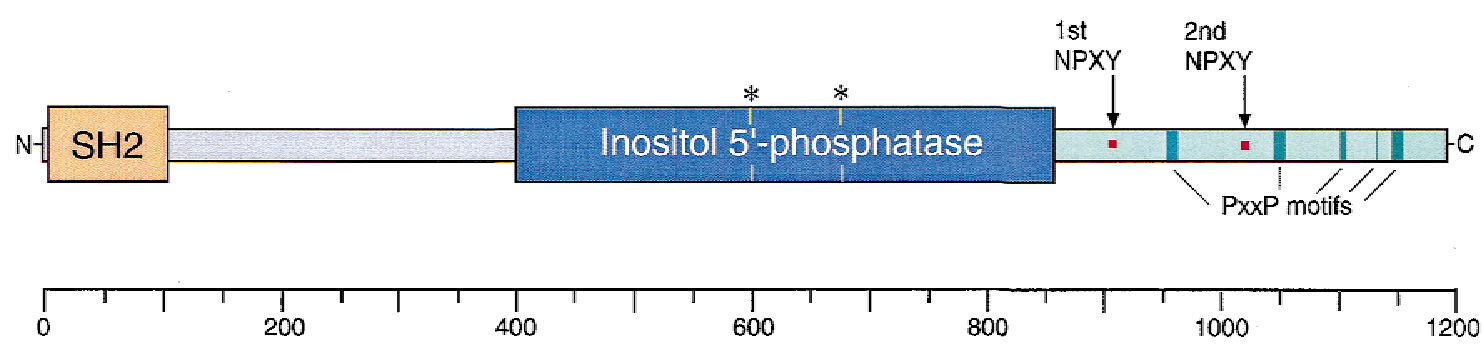

Figure 1. The domain structure of p145 SHIP. The SH2, inositol 5'-phosphatase, and carboxy-terminal domains are shown in light orange, blue, and green, respectively. The region between the SH2 and inositol 5'-phosphatase domains is of unknown function and is shaded gray. Two asterisks above the central enzymatic domain mark the locations of homology regions with all 5'-phosphatases; and two NPXY motifs, when tyrosine phosphorylated, have potential for binding PTB or possibly SH2 domains. These are designated with red in the carboxy-terminal region. The remainder of the carboxy-terminal domain has several potential polyproline motifs (PxxP) for binding SH3 domains. These polyproline motifs are shown in dark green. Three of the motifs show very good consensus for SH3 domain binding; two others have weaker homology and are shown with narrower dark green bands. The scale below the SHIP domain structure designates its length in amino acids.

the more likely SH3-domain binding sites. Together, these structural features describe a unique signaling protein, whose functional significance will be dependent upon the subsequent interactions and enzymatic activity. Each of these aspects of SHIP will be discussed in the following sections.

\section{SHIP isoforms-an armada of SHIPS}

The endogenous SHIP protein is usually detectable as multiple protein bands upon PAGE, with a $145-\mathrm{kD}$ species as the largest band consistently detected. A lower abundance $160-\mathrm{kD}$ SHIP protein has been observed at times (Ono et al. 1996; Geier et al. 1997), but detection may be cell-type or antibody specific, and further characterization has not been reported. Full-length SHIP, 1190 amino acid residues, is the product of a 3570nucleotide ORF. However, SHIP protein products (either endogenous or exogenously expressed) frequently exhibit discrete size variability. In general, SHIP proteins of 145 , 135,125 , and $110 \mathrm{kD}$ have been described in different laboratories (Lioubin et al. 1996; Ono et al. 1996; Lucas and Rohrschneider 1999). The significance of these SHIP isoforms was enhanced by the observation that bone marrow or immature hematopoietic cell lines express increasingly larger SHIP proteins as differentiation proceeds to mature blood cells (Geier et al. 1997). Therefore, the provenance of these isoforms is an important question in determining the function of the SHIP proteins.

Possible mechanisms for isoform production include alternative transcriptional initiation, alternative translational initiation, mRNA splicing, protein degradation, and post-translational modification such as phosphorylation. Several of these possibilities have been examined. A study by Damen et al. (1998) used several domainspecific anti-SHIP antibodies to show that the SHIP protein is subject to specific proteolytic degradation from the carboxy-terminal end, possibly by a member of the calpain family. Several discrete protein bands were observed following expression of the cDNA for p145 SHIP. The smallest SHIP protein obtained, p110, was associated with the cellular cytoskeleton.
Kavanaugh et al. (1996) described a 110-kD form of SHIP in human cells, SIP-110, proposed to be a product of alternative splicing (Fig. 2). SIP-110 lacks the 214 aminoterminal amino acids, including the SH2 domain. The SIP-110 protein is not tyrosine phosphorylated after growth factor stimulation and was identified through its binding to the SH3 domain of Grb2 in a phosphotyrosine-independent manner, showing its ability to participate in interactions despite its lack of an SH2 domain. Although 110-kD forms of SHIP are seen in murine cells, it has not been demonstrated that these forms are the result of SIP-110 or a SIP-110-like mRNA splice. On the other hand, at least part of the postulated splice is consistent with the exon-intron SHIP genomic information and would link a unique nucleotide sequence encoding a start methionine plus eight amino acids to the beginning of exon 6 before the 5'-phosphatase domain (I. Wolf, D.M. Lucas, P.A. Algate, and L.R. Rohrschneider, in prep.). Alternatively, Kerr et al.(unpubl.) have identified a very similar SHIP cDNA encoding a related p110 product (GenBank accession no. AF184912); however, this latter SHIP protein would not require splicing but would arise from utilization of a transcriptional start different than that used for p145 SHIP. Presumably, a second promoter within the SHIP locus would regulate transcription for this $\mathrm{p} 110$ SHIP.

In our laboratory RT-PCR analyses using SHIP-specific oligonucleotides identified a SHIP cDNA with an internal 183-nucleotide deletion immediately following the first NPXY motif (Lucas and Rohrschneider 1999). When translated, this deletion results in the elimination of 61 amino acids after which SHIP translation proceeds in-frame. Because the deleted fragment contains intron splice donor and acceptor consensus sequences, it is likely to be the result of specific mRNA splicing. Several cDNAs encoding the $\Delta 183$ SHIP protein have been cloned from a murine myeloid cell library. The product of this $\Delta 183$ mRNA is calculated to be $8 \mathrm{kD}$ smaller than full-length SHIP, correlating well with observations from immunoblot data showing a p135 SHIP isoform. Further studies using RT-PCR showed that this $\Delta 183$ cDNA is present in all of the full-length SHIP-expressing 
A

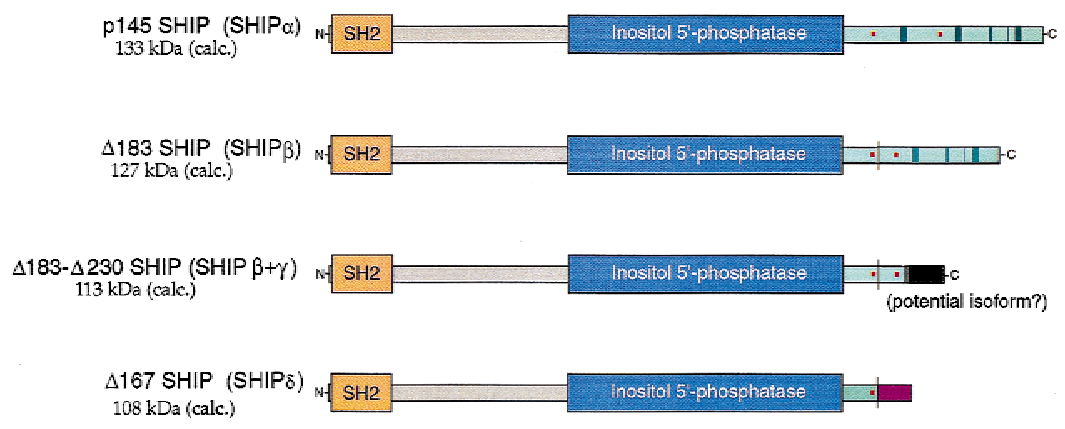

SIP-110
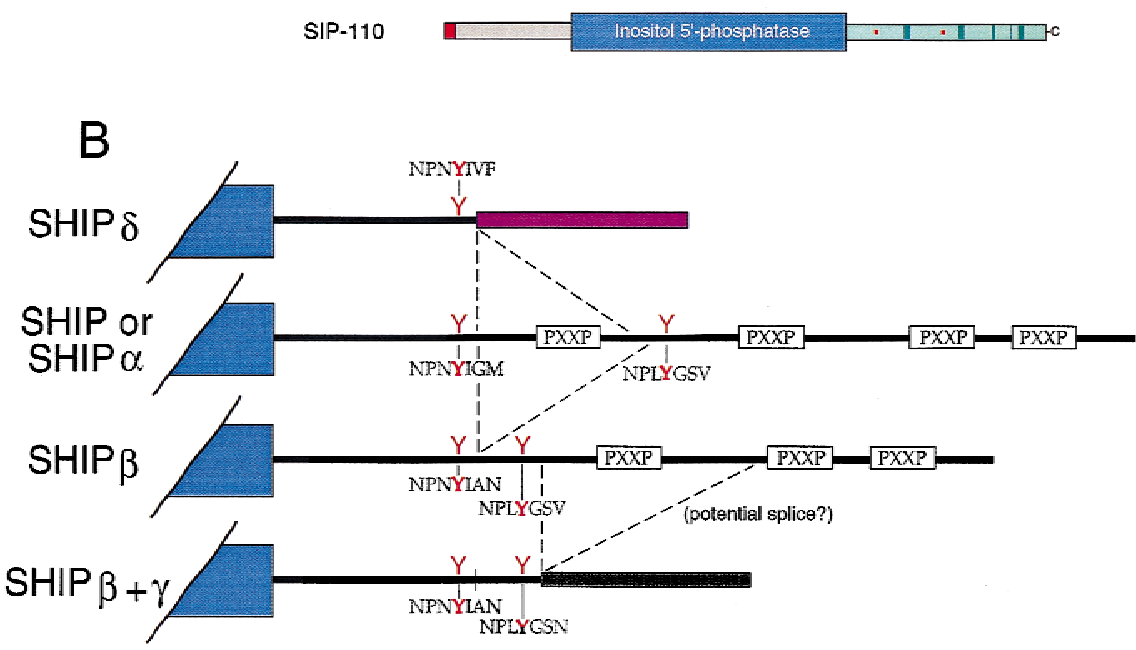

Figure 2. SHIP protein isoforms and derivation of the spliced protein products. $(A)$ The structure of five SHIP isoforms is shown with p145 SHIP (SHIP $\alpha)$ at the top, followed in descending order by smaller size SHIP isoforms. The second structure down (SHIP $\beta$ ) is an in-frame spliced product deleting 183 nucleotides, which affects the amino acids between the two NPXY motifs. The third SHIP isoform contains two spliced-out regions, $\Delta 183$ and $\Delta 230$; the latter removes 230 additional nucleotides from the region immediately downstream of the second NPXY motif in the SHIP. The out-of-frame $\Delta 230$ deletion would produce a protein with 67 new carboxy-terminal amino acids (dark green), and the protein product of this modification alone would be designated SHIP $\gamma$. The mRNA and protein for this latter splice are yet uncharacterized and the protein product should be considered as potential. The SHIP $\delta$ protein results from another out-of-frame splice in the region encoding the carboxyl terminus and produces 41 new amino acids at the carboxyl terminus (purple). An additional SHIP isoform, lacking the SH2 domain, has been called SIP-110. This product is proposed to result from splicing, but this possibility is controversial. (B) Derivation of the SHIP isoforms by splicing reactions. Details of the protein structures affected by splicing within the region encoding the carboxyterminal domain of SHIP are shown. SHIP

(or SHIP $\alpha$ ) is the longest protein, and the other isoforms are derived from this product. The location of four polyproline motifs are shown, and the tyrosine $(\mathrm{Y})$ of the two NPXY motifs are in red. The amino acid sequences surrounding each $\mathrm{Y}$ are shaded gray with the relevant $\mathrm{Y}$ in red. Both $\Delta 167$ and $\Delta 183$ splices begin at the same nucleotide, but terminate at different sites resulting in production of SHIP $\delta$ and SHIP $\beta$, respectively. The $\Delta 183$ splice is in-frame; the $\Delta 167$ is out-of-frame producing the new carboxy-terminal tail sequence (purple). The $\Delta 230$ splice, shown at the bottom, also would produce an out-of-frame deletion with a new C-terminal sequence of 67 amino acids (dark green). Both $\Delta 183$ and $\Delta 230$ splicing would begin at a site near the first or second NPXY motifs, respectively, and change the three amino acid motif on the carboxyl side of each Y. Therefore, both $\Delta 183$ and $\Delta 230$ splices have the potential for altering any SH2 domains binding to these phosphorylated sites but the PTB domain sites remain the same.

cells tested so far, and thus does not appear to be subject to separate regulatory mechanisms. Using several SHIPspecific monoclonal antibodies, we were able to demonstrate that the $135-\mathrm{kD}$ form of SHIP seen by SDS-PAGE is the product of $\Delta 183$ message and identical to p135 SHIP. An additional monoclonal antibody (P2A8) made using an immunogen spanning the spliced junction independently confirmed these results (Lucas and Rohrschneider 1999). The amino acid sequence removed by the $\Delta 183$ splice contains several PxxP sequences. In addition, the splice junction changes the third amino acid downstream of the phosphorylated Y in the first NPX $\underline{Y}$ motif. This change could have significance for altering the specificity of binding via SH2 domains; however, at present, the potential for SH2 domain-containing proteins binding to this site is not well understood.

A SHIP-spliced form similar to the murine $\Delta 183$ is also present in human myeloid cells. This human SHIP was detected by RT-PCR analysis in human ML-1 cells treated with TPA and in human peripheral blood leukocytes. The deletion in the human cells is slightly larger and lacks 282 nucleotides, including those encoding the first NPXY motif. These 282 nucleotides encompass an entire exon instead of the intraexonic splice observed in the murine gene. Like the $\Delta 183$ deletion, the $\Delta 282$ deletion remains in the original reading frame following the splice but produces a SHIP cDNA isoform, which if translated, would lack 94 amino acids totaling $10 \mathrm{kD}$ (Lucas and Rohrschneider 1999). A SHIP polyclonal antibody detects a $135-\mathrm{kD}$ band in human hematopoietic cells, but we have not yet confirmed that this corresponds to the $\Delta 282$ human SHIP. The biological significance of the p135( $\Delta 183)$ SHIP isoform is not yet understood, but because both human and murine forms appear to delete or modify the first NPXY motif along with the deletion of a potential SH3-binding motif, it is likely that at least part of its function relates to protein(s) binding to this region. 
Two additional SHIP splice variants have been detected in the murine myeloid cells. A 167-nucleotide deletion of SHIP beginning at the same nucleotide as the $\Delta 183$ deletion, but ending 16 nucleotides before that of $\Delta 183$, has been characterized (I. Wolf, D.M. Lucas, P.A. Algate, and L.R. Rohrschneider, in prep.). This deletion is also flanked by consensus splice donors and acceptors and appears to be the result of mRNA splicing. However, following the splice, the sequence continues in a different reading frame and produces 41 unique amino acids at the carboxyl terminus before reaching a stop codon. The calculated size of this $\Delta 167 \mathrm{cDNA}$ is $108 \mathrm{kD}$, potentially explaining one of the multiple $110-\mathrm{kD}$ bands seen in murine SHIP immunoblots. An additional splice event has been observed by RT-PCR analysis just downstream of the region encoding the second NPXY motif; however, it has not been characterized further and its existence in vivo is uncertain. This potential splice would delete 230 nucleotides in the last coding exon with a frameshift in translation. Splice donor and acceptor nucleotides flank the deletion, and the proposed splice junction would change the third amino acid on the carboxy-terminal side of the phosphorylated Y in the second NPXY motif. Thus, there might be some recapitulation of translational modifications at both the first and second NPXY motifs; however, the latter splice modification is speculative.

\section{SHIP nomenclature}

Several aspects of SHIP expression present a difficulty in nomenclature. Protein degradation of p145 SHIP protein from the carboxyl terminus creates multiple distinct SHIP proteins as described by Damen et al. (1998), and multiple SHIP splicing can generate SHIP proteins each unique from those created by proteolytic degradation. In addition, the proteolytic degradation of SHIP also may occur on each spliced form of SHIP identified. One example is the $\Delta 183$ SHIP cDNA encoding a $135-\mathrm{kD}$ SHIP protein. A similar size SHIP band is detected as a degradation product from the $145-\mathrm{kD}$ full-length SHIP, but these two $\sim 135-\mathrm{kD}$ proteins are distinguishable by using several monoclonal antibodies (Lucas and Rohrschneider 1999|. These numerous SHIP proteins, plus the cloning of a new homolog, SHIP2 (Pesesse et al. 1997), indicates that a better nomenclature is required.

The body of SHIP literature is large and rapidly growing, and because of the number of references to the 145$\mathrm{kD}$ form as SHIP, no modification needs to be made to this designation. However, recently published work refers to this form as SHIP1 to differentiate it from the newly described SHIP2 (Pesesse et al. 1997). To permit better identification of the multiple smaller spliced isoforms of SHIP1, we propose that these be labeled with Greek letters by their successively smaller size, as has been done with other protein systems. Thus, the $145-\mathrm{kD}$ product can be named SHIP, SHIP1, or SHIP $\alpha$; the product of the $\Delta 183$ deletion can be termed SHIP $\beta$; the 125 $\mathrm{kD}$ SHIP (if characterized better in vivo) can be referred to as SHIP $\gamma$; and the newly described $\Delta 167$ spliced form can be termed SHIP. These designations of each SHIP isoform along with its structure are listed in Figure 2.

\section{Expression}

SHIP was initially detected in the more mature cells of the blood, but it is now apparent that almost all cells of the bone marrow and blood express at least one form of this protein. The presence of SHIP mRNA has been detected at the earliest stages of hematopoietic cell development in mouse embryos (Q. Liu et al. 1998), and protein expression has been observed in all blood cell lineages, to various degrees, using flow cytometric analysis of bone marrow and blood (Geier et al. 1997). This latter study also demonstrated the differential expression of various SHIP isoforms during differentiation of the human ML-1 myeloid leukemia cell line from an immature myeloid state to mature macrophages or granulocytes. The immature cells expressed a p110 SHIP isoform primarily (e.g., SHIP $\delta$ ), whereas the mature cells expressed mostly SHIP $\alpha$ and SHIP $\beta$. This expression pattern also was observed in murine bone marrow cells and mature macrophages derived from these bone marrow cells (Lucas and Rohrschneider 1999). These results indicate complex splicing events for SHIP expression during hematopoietic cell development, with potentially different functions for each isoform and cell lineage.

Many reports have demonstrated SHIP mRNA expression in tissues such as spleen, testis, liver, lung, and brain by Northern blot analysis. This method of analysis is prone to contaminations with blood cells and should also be combined with histochemical detection. Q. Liu et al. (1998) performed both analyses and demonstrated SHIP expression primarily in cells of the blood and testes. Within the testes, SHIP-positive cells were restricted to the spermatids and localized to the cell membrane. The function of SHIP in spermatogenesis is not yet known.

\section{SHIP enzymatic activity}

\section{Inositol 5'-phosphatase}

The central enzymatic domain of SHIP was identified by its sequence similarity to previously identified inositol phosphatases and is tightly conserved (96\% identical) between murine and human SHIP (Ware et al. 1996; Geier et al. 1997). Its enzymatic activity removes the phosphate group from the $5^{\prime}$ position of both phosphatidylinositol 3,4,5-trisphosphate $[\mathrm{PI}(3,4,5) \mathrm{P} 3]$ and 1,3,4,5-tetrakisphosphates $\left(\mathrm{IP}_{4}\right)$ (Damen et al. 1996; Lioubin et al. 1996). The $3^{\prime}$ position of the inositol phospholipid must be phosphorylated before SHIP can dephosphorylate the $5^{\prime}$ position (Damen et al. 1996) suggesting that SHIP acts sequentially with phosphatidylinositol 3' kinase (PI3'K) in an inositol phospholipid pathway. This $5^{\prime}$-phosphatase activity is not regulated by tyrosine phosphorylation or interaction with adaptor proteins. Rather, it is believed that localization is the determining factor in its 
mechanism of action. Upon cell stimulation with a growth factor, cytoplasmic SHIP is transported to sites near the lipid substrates at the plasma membrane.

Most assays for SHIP enzymatic activity have been in vitro. However, when inositol phospholipids have been quantified from cells either lacking SHIP or induced for tyrosine phosphorylation of SHIP, the results have consistently supported the in vivo role for SHIP in the conversion of PI(3,4,5)P3 to PI(3,4)P2 (Giuriato et al. 1997; Scharenberg et al. 1998; Gupta et al. 1999; Huber et al. 1999; Liu et al. 1999).

\section{SHIP homologs}

SHIP belongs to a family of inositolpolyphosphate phosphatases, comprised of two major classes: the general class of inositol phosphatases and the more closely related SH2-containing 5 '-phosphatases. The former class of general inositol phosphatases can be subdivided further into those proteins removing phosphate from positions other than the $5^{\prime}$ position on the inositol ring, and a more related group composed of inositol 5'-phosphatases only (Majerus et al. 1999). All inositol 5'-phosphatases (including SHIP and SHIP2) contain two main amino acid sequence motifs defining this class of enzymes. Thus, the SHIP family tree shows the closest relationship to other SH2-containing inositol 5'-phosphatases, followed by the general class of inositol 5 '-phosphatases (lacking an SH2 domain), and finally, all other inositol phosphatases removing phosphate from positions not including $5^{\prime}$ on the inositol ring. The SHIP homologs and their relationships will be discussed in order of descending relationship to SHIP itself.

The closest relative to SHIP is called SHIP2, and both proteins contain the same major structural features and exhibit an overlapping tissue expression pattern (Pesesse et al. 1997; Wisniewski et al. 1999). SHIP2 was originally cloned as a product potentially complementing the Fanconi anemia group A gene defect (Hejna et al. 1995), but the SH2 domain was not included in this clone. This gene product was called 51C. Interestingly, one strategy for the original cloning of SHIP employed the PTB domain of Shc to recognize tyrosine-phosphorylated target proteins from myeloid cells. In addition to SHIP itself, the $51 \mathrm{C}$ protein was identified as a Shc PTB domain target in the same screen (Lioubin et al. 1996). Subsequent work with myeloid cells identified the complete cDNA for 51C and renamed the product SHIP2 (Pesesse et al. 1997; Wisniewski et al. 1999).

The SHIP2 protein exhibits highest amino acid identity to SHIP: $\sim 38 \%$ overall identity. The highest identity occurs within the $5^{\prime}$-phosphatase domains (64\%), with slightly less identity in the amino-terminal SH2 domains $(54 \%)$. The carboxy-terminal region of SHIP2 exhibits even less identity; however, all of the sequence motif hallmarks of SHIP are present including numerous polyproline regions (perhaps eight) for potential SH3-domain binding, and a single NPXY motif, which no doubt accounts for Shc binding through its PTB domain. SHIP2 protein is observed as a $155-\mathrm{kD}$ protein on polyacryl- amide gels, and it is not known whether the $160-\mathrm{kD}$ protein seen in some SHIP preparations represents antigenic cross-reactivity with SHIP2. Despite their similarities, important differences between these two proteins have been identified. First, although SHIP's expression is restricted to hematopoietic and spermatogenic cells, SHIP2 expression is much more ubiquitous with primary expression not only in blood cells (Pesesse et al. 1997; Bruyns et al. 1999) but also in skeletal muscle, heart, placenta, and pancreas. Second, although enzymatic activity of both SHIP homologs requires that its phosphoinositide substrate have the $3^{\prime}$ position phosphorylated, presumably by PI3'K, 5' -phosphatase assays demonstrate that these two proteins exhibit different substrate specificity. Only SHIP removes the 5' phosphate from both $\mathrm{PI}(3,4,5) \mathrm{P} 3$ and the soluble Ins $(1,3,4,5) \mathrm{P}_{4}$; whereas SHIP2 utilizes the PI(3,4,5)P3 substrate only (Wisniewski et al. 1999). These data suggest that SHIP and SHIP2 may not be completely redundant in function and that, even when expressed in the same cell, each may either regulate different pathways of inositide metabolism or interact differently with downstream effector proteins.

The presence of one close SHIP homolog suggests that others may yet exist. The existence of additional homologs is plausible considering the ubiquitous distribution of PI3'K, phosphoinositol lipids, and the necessity of their metabolism; however, more distantly related 5'phosphatases could perform some of these functions. At present, evidence for the presence of only one additional potential SHIP homolog in insulin-stimulated CHO cells is available (Guilherme et al. 1996).

Moving down the SHIP homology and function scale, we come to the ubiquitously expressed inositol 5' -phosphatases synaptojanin 1 and 2, the X-linked OCRL loculocerebrorenal-Lowe's) syndrome 5'-phosphatase, and the platelet type II enzyme with similar specificity. The grouping of these enzymes is determined both by lack of an SH2 domain and the presence of $5^{\prime}$-phosphatase enzymatic activity. In this class, however, the substrate does not need to be phosphorylated at the $3^{\prime}$ position of the inositol ring (and is therefore $\mathrm{PI} 3^{\prime} \mathrm{K}$ independent). The synaptojanins are thought to be involved in synaptic vesicle trafficking and form complexes with dynamin and amphiphysin to promote vesicle recycling (Cremona et al. 1999; McPherson et al. 1996; Chung et al. 1997b; Nemoto et al. 1997). Both synaptojanins 1 and 2 have brain-specific and ubiquitously expressed isoforms (McPherson et al. 1996; Khvotchev and Südhof 1998); like SHIP, both are subject to tissue-specific alternative splicing, which alters the carboxy-terminal region of the protein (Seet et al. 1998; Nemoto and De Camilli 1999). In addition to the inositol phosphatase activity, the synaptojanins also possess a carboxy-terminal proline-rich region allowing interaction with $\mathrm{SH} 3$ domains. These multiple synaptojanin forms present an intriguing parallel to SHIP, but their biological function is clearly distinct.

The two additional members of this class, the OCRL/ IP5P and type II IP5P, display $44 \%-52 \%$ similarity to 
SHIP in the catalytic domain but are divergent outside this region and lack the protein-protein interaction motifs found on SHIP (Attree et al. 1992; Lioubin et al. 1996). The OCRL protein is an interesting example of a lipid metabolizing enzyme whose defect leads to an abnormal phenotype in humans: namely, OCRL syndrome characterized by renal failure, mental retardation, and blindness (Kawano et al. 1998). The OCRL protein is expressed broadly, but as the name implies, defects in the X-linked human OCRL gene (destroying the $5^{\prime}$-phosphatase activity) affect primarily lens, brain, and kidney cells. Cells from OCRL patients still express active type II inositol 5'-phosphatase but accumulate PI(4,5)P2. These results suggest the strong compartmentalization of $5^{\prime}$-phosphatases and the importance of inositol lipids in cell physiology.

Much farther down the SHIP homology scale are found a range of inositol phosphatases hydrolyzing the phosphate at positions of the inositol ring not including $5^{\prime}$. Many are not well characterized but include those phosphatases acting on the 1,3 , or 4 positions of the phosphorylated inositol ring. Inositol phosphatases in this class have very little sequence identity to SHIP: however, in this instance, the importance of sequence identity is superceded by other considerations. For example, members of this class of phosphatases probably operate in the same lipid-metabolizing pathway as SHIP. The inositol polyphosphate 4-phosphatases function in a group that metabolize $\mathrm{PI}(3,4) \mathrm{P} 2$, the lipid product produced by SHIP and its substrate PI $(3,4,5) \mathrm{P} 3$ (Norris et al. $1995,1997)$. Another member of this group is the tumor suppressor protein PTEN (for review, see Maehama and Dixon 1999). The phosphatase activity of PTEN removes the phosphate at the $3^{\prime}$ position from $\mathrm{PI}(3,4,5) \mathrm{P} 3$, producing PI(4,5)P2. Like SHIP, PTEN's substrate requires phosphorylation by $\mathrm{PI} 3^{\prime} \mathrm{K}$, but unlike SHIP, the net effect is the apparent reversal of PI3' $\mathrm{K}$ enzymatic activity. Interestingly, even though the 4-phosphatase and PTEN remove phosphate from different sites on the inositol ring, both have the same amino acid sequence motif at the active site, $\mathrm{C}(\mathrm{X})_{5} \mathrm{R}$ (Zhang et al. 1994; Zhou et al. 1994; Fauman and Saper 1996). SHIP and SHIP2, exhibiting little overall sequence relationship to the 4-phosphatase or PTEN, both contain, in addition to the two signature motifs for the $5^{\prime}$-phosphatase family (Majerus et al. 1999), the related amino acid sequence motif $\mathrm{C}(\mathrm{X})_{5} \mathrm{~K}$. The second signature motif is probably the phosphatase active site and the $\mathrm{C}(\mathrm{X})_{5} \mathrm{~K}$ motif may be part of that active site. It is not known whether the additional $\mathrm{C}(\mathrm{X})_{5} \mathrm{~K}$ motif has any role in the $5^{\prime}$-phosphatase enzymatic activity.

Analysis of genomic sequencing databases have revealed no identifiable nonmammalian homologs of SHIP. Members of the $5^{\prime}$-inositol phosphatase family have been found in Caenorhabditis elegans and Drosophila melanogaster; however, these sequences lack the protein-protein interaction motifs that make the SHIP protein unique. The lack of close SHIP homologs in these organisms suggests that SHIP may be a late evolutionary modification.

\section{SHIP interactions with other proteins}

As described above, the protein structure of SHIP contains numerous recognizable protein-protein interaction motifs. As in any signaling pathway, the function of SHIP must depend on its interaction with other upstream proteins, as well as downstream effector proteins and potential regulatory interactions. The observation that the different isoforms of SHIP either delete or otherwise modify these motifs further suggests that these regions play important individual roles in guiding the function of SHIP and that this function can be tailored by expressing these different isoforms. The following is an examination of the known and potential protein binding partners interacting with SHIP.

\section{ITIM/ITAM motifs}

The amino-terminal SHIP SH2 domain binds to phosphotyrosine residues and is a key feature mediating the interactions of numerous signal transduction proteins. A screen of a degenerate phosphopeptide library has shown a SHIP SH2 domain preference for a $\mathrm{pY}(\mathrm{Y} / \mathrm{D} / \mathrm{X} / \mathrm{L} / \mathrm{I} / \mathrm{V})$ motif on target proteins (Osborne et al. 1996). This target motif matches sequences found in the so-called immmunoreceptor tyrosine-based activation motif (ITAM, YXXLX $_{6-8}$ YXXL in single-letter amino acid code) and the immunoreceptor tyrosine inhibition motif [ITIM, (V/ I)XYXX(L/V)] (for review, see Unkeless and Jin 1997). During B-cell activation, the ITAM located on the cytoplasmic tail of the B-cell receptor (BCR) becomes phosphorylated on tyrosine and coordinates a proliferative signal in response to engagement and coclustering of BCRs by soluble-immunoglobulin bound to antigen (Kurosaki 1999|. This is a critical first step in positive activation of naive B cells. Negative signaling in B cells is mediated by the Fc $\gamma$ RIIB receptor. The binding of the SHIP SH2 domain to the ITIM motif of FcyRIIB is an important component of this negative signaling (Ono et al. 1996; Tridandapani et al. 1997; Coggeshall 1998) and will be discussed in greater detail below.

The ITIM motif is a component of the killer cell inhibitor receptors (KIR) found on natural killer (NK) and T cells (for review, see Saito 1998) and the KIR-like receptor gp49B1 on mast cells (Kuroiwa et al. 1998). However, whereas SHIP does not bind the ITIM of the KIR on NK cells (Gupta et al. 1997; Vély et al. 1997), it does bind the ITIM motif of gp49B1. Interestingly, gp49B1 contains two ITIM motifs, and SHIP displays a preference for binding to the ITIM proximal to the carboxyl side of the receptor. Additionally, the platelet cell endothelial adhesion molecule 1 (PECAM-1 or CD31) also contains two ITIM motifs, and SHIP has been shown to have preferential binding to just one of these. Therefore, it appears that the binding of the SHIP SH2 domain to ITIM sequences is not promiscuous and is possibly restricted by additional amino acid residues outside the ITIM motif unique to each protein.

The SH2 domain of SHIP also binds to ITAM motifs of the Fc $\gamma$ RIIa and Fc $\gamma$ RI-associated $\gamma$ chain on monocytes 
(Maresco et al. 1999), the FceRI $\gamma$ chain on mast cells, the CD3 complex, and the T-cell receptor $\zeta$ chain (Osborne et al. 1996). However, these interactions have only been suggested through in vitro binding studies. With the exception of SHIP binding to Fc $\gamma \mathrm{RI}$ /discussed in detail below) the biological relevance of these interactions with ITAM-containing receptors is unknown.

\section{SHP-2}

The protein tyrosine phosphatase SHP-2 has been reported to interact with the SH2 domain of SHIP (Sattler et al. 1997; L. Liu et al. 1997b). In one of these reports, it was demonstrated that IL-3 stimulation of B6SUtA1 cells results in the coimmunoprecipitation of SHIP and SHP-2 and that the SHIP SH2 domain alone was able to precipitate SHP-2 from cell lysates. As with other studies of this type, these data do not completely rule out the possibility that this association could be indirect and mediated by other molecules. Regardless of how the interaction takes place, both reports suggest that the association of SHIP with SHP-2 is exclusive of the well-described SHIP-Shc interaction. Furthermore, the oncogene $B C R-A B L$ shifts the association in favor of the SHIP-SHP-2 complex, in which $B C R-A B L$ also participates (Sattler et al. 1997). SHIP is rapidly tyrosine phosphorylated and dephosphorylated following growth factor stimulation, and the potential significance of the SHIP-SHP-2 interaction may reside in the possibility that SHP-2 is responsible for the observed dephosphorylation of SHIP or a protein associated with SHIP.

\section{Gab family proteins}

Gab family members, including Gab1 and Gab2 in mammalian cells and DOS in Drosophila, are scaffolding proteins that participate in many signaling pathways activated by various cytokines and growth factors (for review, see Huyer and Alexander 1999). These molecules contain an amino-terminal pleckstrin homology $(\mathrm{PH})$ domain, a central proline-rich domain and multiple tyrosine phosphorylation sites spanning the length of the protein, which act as docking sites for the $\mathrm{SH} 2$ domaincontaining proteins. Direct associations of Gab family members with Grb2, p85-subunit of PI3-kinase and the tyrosine phosphatase SHP-2 have been found in diverse signaling pathways (Holgado-Madruga et al. 1996; Carlberg and Rohrschneider 1997; Gu et al. 1998; Nishida et al. 1999). Recently, it was found that SHIP can also form complexes with Gab family members. An association of SHIP with Gab1 and Gab2 was detected in EPO-stimulated UT-7 cells and M-CSF-stimulated FD/fms cells, respectively (Lecoq-Lafon et al. 1999; Y. Liu, B.J. Jenkins, and L.R. Rohrschneider, in prep.). The interactions between SHIP and tyrosine phosphorylated Gab family members are presumably through the $\mathrm{SH} 2$ domain of SHIP. In support of this hypothesis, we found that a GST-fusion protein of the SHIP- SH2 domain is sufficient to pull down Gab2 after M-CSF stimulation in FD/ fms cells (Y. Liu, B.J. Jenkins, and L.R. Rohrschneider, in prep.). However, it is still not clear whether the interactions are direct or through proteins such as Grb2, p85/ $\mathrm{PI}^{\prime} \mathrm{K}$, or SHP-2. More experiments, including in vitro binding assay and mutant analyses, are required to address this question and, more importantly, to explore the functional significance of the interaction between these two interesting molecules.

\section{Shc and Grb2}

Shc and Grb2 are ubiquitously expressed adaptor proteins, first identified as important mediators of growth factor receptor signaling through the Ras/MAPK pathway (Rozakis-Adcock et al. 1992; for review, see Lewis et al. 1998). The SH3 domain of Grb2 presumably interacts with one of the polyproline motifs in the SHIP carboxyl terminus (Damen et al. 1996), and the PTB domain of Shc binds to the tyrosine-phosphorylated NPXY motifs in SHIP (Lamkin et al. 1997). In vitro pull-down experiments using GST fused to the SHIP SH2 domain and synthetic phosphopeptides provide evidence that tyrosine-phosphorylated Shc can also bind to the SHIP SH2 domain directly (L. Liu et al. 1997a; Pradhan and Coggeshall 1997; Tridandapani et al. 1999). In vivo data support this model of SHIP-Shc interaction because experiments show that SHIP mutated at the $\mathrm{SH} 2$ domain is incapable of coimmunoprecipitaing Shc from a murine hematopoietic cell line, whereas wild-type SHIP can (L. Liu et al. 1997a). However, the interpretation of this work is difficult, as the mutated SHIP also fails to become tyrosine phosphorylated in response to IL-3 stimulation like wild-type SHIP. Therefore, the decrease in Shc binding may arise due to decreased phosphorylation of the SHIP NPXY motifs mediating Shc PTB domain binding and may not represent a direct interaction with the $\mathrm{SH} 2$ domain.

Mechanistically, it would seem unnecessary for SHIP to bind to She through both the $\mathrm{SH} 2$ domain and the NPXY motifs. However, Tridandapani et al. (1999) have observed that isolates of Fc $\gamma$ RIIB contain SHIP but not Shc, whereas isolates of Shc contain SHIP but not FcyRIIB. This suggests that Shc binding is somehow excluded from SHIP binding when the SHIP SH2 domain is engaged to Fc $\gamma$ RIIB. From this work, Tridandapani et al. have proposed a model for Fc $\gamma$ RIIB-mediated signaling in which the SH2 domain of SHIP first engages the Fc $\gamma$ RIIB. SHIP is then phosphorylated at the NPXY motifs by an undefined kinase, and the PTB domain of Shc interacts with SHIP. Shc then becomes tyrosine phosphorylated itself (Ingham et al. 1999), promoting the interaction of the SHIP SH2 domain with Shc. This would sever the interaction of SHIP with FcyRIIB through the SHIP SH2 domain and thereby remove SHIP activity at the receptor. This is an intriguing hypothesis, and clearly, the interaction of the SH2 domain of SHIP and Shc demands further investigation.

Shc is also a ligand for Grb2, with the SH2 domains of Grb2 binding to phosphorylated tyrosine residues on Shc. This situation raises several questions. Do SHIP, 
Shc, and Grb2 form a heterotrimeric complex, or does the binding of just two of these molecules preclude the binding of the third member? Data from Harmer and DeFranco (1999), employing a Grb2-deficient cell line, suggest that efficient binding of SHIP and She requires Grb2, in a situation analogous to the Sos/Shc/Grb2 complex formation. She and Grb2 together form a complex with Sos as part of the Ras/MAPK pathway. The binding of SHIP to Shc and Grb2 may interfere with the Sos/Shc/ Grb2 complex formation and subsequently block activation of the Ras pathway. Fc $\gamma$ RII-mediated negative signaling in B cells is associated with a decrease in Ras activation accompanied by a decrease in Shc/Grb2/Sos formation (Tridandapani et al. 1997). Whether SHIP may be involved in this function by acting as a competitor for $\mathrm{Shc} / \mathrm{Grb} 2$ binding versus Sos is unclear. Activation of the MAPK cascade seems unaffected in chicken B cells that do not express SHIP (Okada et al. 1998). Additionally, although microinjection of SHIP into Xenopus oocytes blocks activation of the MAPK pathway induced by insulin, injection of a catalytically inactive SHIP does not, suggesting that this inhibition is dependent on the inositol phosphatase domain of SHIP and not any portions of SHIP mediating Shc and Grb2 interactions (Deuter-Reinhard et al. 1997).

Perhaps the simplest explanation for why SHIP binds Shc and Grb2 is because these adaptors serve to localize SHIP to various destinations inside the cell. Shc and Grb2 are known to interact with a variety of membranebound proteins; therefore, SHIP may employ interactions via these adapters to become localized to the cell membrane, where the substrates for its catalytic activity reside. Alternatively, the combination of Shc and Grb2 is linked to not only Sos and SHIP, but also to the Gab family of proteins and numerous growth factor receptors. This suggests that Shc and Grb2 together may be involved in a common, perhaps universal, mechanistic step, which is currently not appreciated.

\section{PI3'K}

PI3' $\mathrm{K}$, the enzyme responsible for $\mathrm{PI}(3,4,5) \mathrm{P} 3$ production, is a heterodimer of a $85-\mathrm{kD}$ regulatory subunit and a $110-\mathrm{kD}$ catalytic subunit. The $\mathrm{p} 85$ subunit of PI3'K contains two SH2 domains, both with similar binding specificity $[\mathrm{pY}-(\mathrm{M} / \mathrm{V} / \mathrm{I} / \mathrm{E})-\mathrm{x}-\mathrm{M}]$ when tested against tyrosinephosphorylated peptide motifs in vitro (Felder et al. 1993; Songyang et al. 1993). Interestingly, a p85 SH2domain recognition motif is present in SHIP as the sequences immediately adjacent to the tyrosine of the first NPXY motif (i.e., NPXpYIGM). Experiments using a GST-p85 SH2 fusion protein show that this domain binds to full-length tyrosine-phosphorylated SHIP, but not to nonphosphorylated SHIP (Gupta et al. 1999; Lucas and Rohrschneider 1999). The SHIP $\beta$ isoform retains the NPXpY motif, but the upstream splice junction near the 3' side of this motif disrupts the potential p85 SH2-domain binding motif by changing the amino acid sequence to NPXpYIAN. The sequence alteration in this motif results in the decreased ability of the p85 SH2 domain binding to SHIP $\beta$. The association of $\mathrm{p} 85 / \mathrm{PI} 3{ }^{\prime} \mathrm{K}$ with SHIP could represent an interesting complex of enzymes favoring the conversion of $\mathrm{PI}(4,5) \mathrm{P} 2$ to $\mathrm{PI}(3,4,5) \mathrm{P} 3$, and finally, $\mathrm{PI}(3,4) \mathrm{P} 2$. Such conversion may be important in signaling for the membrane localization, or turnover of various $\mathrm{PH}$ domain-containing proteins. On the other hand, the human SHIP protein contains a slightly different motif at this site and its association with $\mathrm{p} 85$ has not been tested. Support for the biological significance of the SHIP-p85/PI3'K interaction would be greatly enhanced if $\mathrm{p} 85$ were also found to interact with the human SHIP.

\section{PIAS1 interaction with SHIP}

In our laboratory, the carboxyl tail of SHIP was used as bait in a yeast two-hybrid screen to look for murine hematopoietic-cell proteins interacting with the SHIP tail. No exogenous protein kinase activity was incorporated into the screen, and it was therefore anticipated that target proteins might contain SH3 domains or interact with the SHIP carboxyl tail via other nonphosphorylated amino acid sequences. The screen identified five interacting proteins; three of these each contained at least one SH3 domain. Not surprisingly, Grb2 was one of these proteins. Two additional SH3 domain-containing adaptor proteins were obtained, one of which was novel. Also identified in the same screen was an interaction between SHIP and a protein inhibitor of STAT1 called PIAS1 (protein inhibitor of activated STATㅅ) (B. Liu et al. 1998). Biochemical analyses have demonstrated that SHIP and PIAS1 interact constitutively in the unstimulated monocytic precursor cell line FD/Fms (J.F. Fuller and L.R. Rohrschneider, in prep.). Furthermore, PIAS1 interacts directly with the nonphosphorylated carboxyl terminus of SHIP, and conversely, SHIP interacts only with PIAS1 and not the PIAS3 homolog (Chung et al. 1997a). Given the large number of protein interaction sites within the SHIP carboxyl terminus, further effector or regulatory proteins of SHIP inteacting with this domain are likely to be identified.

\section{$D A B-1$}

The neuronal protein Dab-1 binds via its PTB domain to the NPXY motifs on SHIP in vitro (Howell et al. 1999). Dab-1 is expressed in both neuronal and hematopoietic cells and could interact with SHIP in the blood cells. Dab-1 binds both membrane inositol phospholipids and transmembrane receptors in neuronal cells, and thus may link receptor signaling with phosphatidylinositol polyphosphate metabolism. A physical interaction between SHIP and Dab-1 in vivo has not been reported; although an association would be interesting, it remains speculative.

\section{General biology of SHIP proteins}

SHIP is tyrosine phosphorylated and participates in signaling by a large number of hematopoietic growth fac- 
tors and cytokines. Despite this contribution to very early events in apparent positive growth factor signaling, overexpression studies of p145 SHIP in myeloid cell lines indicated a negative role for SHIP in cell growth (Lioubin et al. 1996), and apoptosis was detected in some SHIPoverexpressing cell lines (L. Liu et al. 1997a). A negative role for SHIP signaling also has been described in B cells (Chacko et al. 1996; Ono et al. 1996; Kiener et al. 1997); however, the biochemical nature for the signaling in the hematopoietic cell types varies considerably. One must therefore wonder whether SHIP interactions are celltype specific, or whether the differences indicate that the details are yet incomplete.

Gene-targeted knockout of SHIP in mice (Helgason et al. 1998; Liu et al. 1999) results in animals that are viable and fertile, but the life span of the homozygous-null animals is decreased due to myeloid cell infiltration of vital organs. Within the SHIP-null animals, a chronic progressive hyperplasia of the granulocytes and macrophages is observed, perhaps at the expense of B-cell production, whereas erythroid cell numbers show little or no change from the SHIP wild-type mice. The increased myeloid cell proliferation in the SHIP-null mice is associated with both increased $\mathrm{PI}(3,4,5) \mathrm{P} 3$ production and the wortmannin-sensitive activation of serine/threonine kinase Akt/PKB. These cells are also less sensitive to apoptosis. Therefore, the most pronounced role for SHIP is in maintaining balanced growth regulation for specific myeloid cells, perhaps through governing the levels of growthstimulated $\mathrm{PI}(3,4,5) \mathrm{P} 3$ and the subsequent activation of Akt/PKB. In the lymphoid cell compartment, the B-cell numbers are also affected by SHIP deficiency, but whether this results from a direct or indirect effect of SHIP is not clear.

\section{SHIP and PTEN}

The role of SHIP in the enzymatic conversion of $\mathrm{PI}(3,4,5) \mathrm{P} 3$ to $\mathrm{PI}(3,4) \mathrm{P} 2$ stimulates the question of whether SHIP is a tumor suppressor like the PTEN protein, which utilizes the same lipid substrate but produces a different lipid product, PI(4,5)P2. Two lines of evidence indicate that SHIP is clearly not a tumor suppressor. First, the PTEN protein is encoded by a chromosomal location (10p23.3) associated in humans with an increased cancer incidence due to abnormalities and loss of heterozygosity (Li et al. 1997; Steck et al. 1997). The human SHIP protein is encoded by a locus (2q36-q37) in which the occasional overt defects (i.e., large deletions) exhibit only sporadic association with tumor formation (Geier et al. 1997). Second, whereas mice heterozygous for a functionally defective PTEN allele incur an increased cancer incidence (exacerbated by sublethal radiation) (Di Cristofano et al. 1998; Suzuki et al. 1998; Podsypanina et al. 1999), mice heterozygous for SHIP loss are virtually normal (Helgason et al. 1998; Liu et al. 1999). Even the homozygous SHIP-null mice do not have an increased susceptibility to cancer; however, the myeloproliferative disorder resulting in a decreased life span may preclude complete assessment of susceptibility changes to cancer in these animals. Nevertheless, despite the fact that SHIP is a negative regulator of cell growth, none of the main hallmarks of tumor suppressor activity indicate that SHIP's function falls within this category.

A more interesting question is why SHIP is not a tumor suppressor like PTEN, as they both have a common lipid substrate-PI $(3,4,5) \mathrm{P} 3$. Part of the answer may be obtained from comparison of knockout animals for each gene: $P T E N^{-/-}$mice exhibit a much more severe phenotype than $S H I P^{-/-}$mice do. The former knockout result in embryonic lethality, whereas the latter mice are physically almost indistinguishable from wild-type mice (but with a shorter life span as discussed above). There are two possibilities for this difference in biological activity. One, the pathology in $S H I P^{-/-}$mice may not be as severe as expected because a SHIP homolog compensates for the loss. The SHIP2 protein is a logical candidate because it too is expressed in blood cells (Pesesse et al. 1997; Wisniewski et al. 1999). Second, the PTEN protein may have a more critical role than SHIP in cell growth and development. Perhaps PTEN performs some additional functions, not overlapping with those of SHIP, thus accounting for the activities of tumor suppression and embryonic lethality. It is not possible to distinguish between these possibilities at present.

\section{Summary of SHIP interactions and possible functions}

The overriding theme for SHIP function has consistently emphasized its negative regulatory role in cell growth and development. SHIP does not appear to be necessary for growth or differentiation per se; however, it has discernible effects on regulating these activities. The experimental specifics of the mechanism for this negative function differ depending upon the hematopoietic cell type and the portion of the SHIP protein under investigation. We will first describe the most prominent mechanisms uncovered for B-lineage cells, mast cells, and myeloid cells, and critically discuss the overall mechanisms.

\section{$B$ cells}

Naive B cells have the innate capability of each expressing one of an extraordinarily large number $\left(\sim 10^{11}\right)$ of antibody specificities on their cell surface encoded as the variable region of the BCR. With such a large antibody repertoire, some specificities will be directed against the individual harboring these B cells, whereas other specificities will be needed to fight infection by various invading microorganisms. B cells expressing BCRs with the former specificity must be eliminated, whereas B cells with the latter BCR specificity should be amplified to provide protection. This occurs through negative and positive selection of individual naive $\mathrm{B}$ cells, respectively.

The proposed positive and negative B-cell signaling 
mechanisms are shown in Figure 3. Positive signaling is observed after BCR cross-linking with multivalent antigen (or Fab' ${ }_{2}$ antibody with specificity for the BCR). Crucial steps in this signaling are PI3' $\mathrm{K}$ activation (Hippen et al. 1997; Kiener et al. 1997), with production of PI(3,4,5)P3 from the more abundant lipid, PI(4,5)P2. The $\mathrm{PH}$ domain of the nonreceptor tyrosine kinase, Btk, binds to PI(3,4,5)P3 with high affinity (Fukuda et al. 1996; Salim et al. 1996; Rameh et al. 1997) and the downstream phospholipid C $\gamma 2$ (PLC $\gamma 2$ ) becomes tyrosine phosphorylated and activated. The subsequent action of PLC $\gamma 2$ on the lipid PI(4,5)P2 produces diacylglycerol and IP3, which activate PKC and induce release of $\mathrm{Ca}^{2+}$ from cytoplasmic stores, respectively. Each of these steps is essential for the positive signals because inhibitors or mutations in critical regions of these proteins eliminates the increased influx of intracellular $\mathrm{Ca}^{2+}$ and the positive signal for growth and further development (Kurosaki 1999).

The positive signal results in amplification of B cells expressing high-affinity antibodies beneficial to the host. However, if an individual B cell is producing a nonbeneficial antibody (e.g., directed against the host), that cell must be eliminated. In that case, the positive signal must be attenuated, and that mechanism is shown in the gray-shaded area of Figure 3. The negative signal is initiated by cross-linking the BCR with the primarily B cellspecific isotype of the FcyRII receptor (e.g., FcyRIIB1). Cross-linking is achieved in vivo when the concentrations of antigen and antibody approach equivalence. In vitro this is achieved by exposure of B cells to intact IgG with immune specificity for the BCR / the Fc portion of the IgG then naturally attaches to the FcyRII). The Fc $\gamma$ RIIB1 receptor contains an immunoreceptor tyrosinebased inhibitory motif (ITIM) in its short 62-amino-acid cytoplasmic tail, and tyrosine phosphorylation of the tail region, by a kinase such as Lyn, marks a docking site for the amino-terminal SHIP SH2 domain. Thus, the consti- tutively active phosphatidylinositol 5 '-phosphatase domain of SHIP is tethered to the cytoplasmic plasma membrane surface where its substrate $[\mathrm{PI}(3,4,5) \mathrm{P} 3]$ is being produced by the activated PI3' $\mathrm{K}$. The SHIP enzymatic activity converts $\mathrm{PI}(3,4,5) \mathrm{P} 3$ to $\mathrm{PI}(3,4) \mathrm{P} 2$ and eliminates the higher affinity binding site for the $\mathrm{PH}$ domain of Btk (Salim et al. 1996; Bolland et al. 1998; Scharenberg et al. 1998). The disruption of the Btk PH domain interaction with the membrane appears sufficient to block positive signaling, because Btk-deficient cells lack the positive response (induced by BCR cross-linking and measured by increased $\mathrm{Ca}^{2+}$ influx and growth stimulation) (Rawlings and Witte 1994; Fluckiger et al. 1998). The positive signal can be reinstated in the Btk-deficient cells by introduction of a wild-type Btk (Fluckiger et al. 1998). Furthermore, spontaneous mutations in broad regions encoding the Btk protein that arise in both humans and mice result in X-linked agammaglobulinemia, a disease characterized by failure of positive B-cell signaling. Individual mutations in the Btk $\mathrm{PH}$ domain alone are sufficient to abrogate the positive growth signal (Conley and Rohrer 1995; Rawlings and Witte 1995). Therefore, the positive signal for B-cell growth and development induced by BCR cross-linking, is substantially attenuated upon coligation of the BCR with Fc $\gamma$ RIIB1. The inositol $5^{\prime}$-phosphatase enzymatic activity of SHIP, tethered to the Fc receptor, depletes the intracellular membrane surface of the $\mathrm{PI}(3,4,5) \mathrm{P}_{3}$ needed for Btk activation. The $\mathrm{Ca}^{2+}$ influx from intracellular sources is prevented and these B cells do not proliferate or develop further.

This mechanism may be close to the truth, but the overall picture is incomplete. The SHIP 5'-phosphatase activity is required for attenuating the positive $\mathrm{Ca}^{2+}$ influx in B-cell signal (Ono et al. 1997), but other domains of SHIP also may be required. For example, the carboxyl terminus of SHIP has the potential for interacting with many different proteins, but its role in negative signaling has not been examined. Perhaps a block in the $\mathrm{Ca}^{2+}$ in-
Figure 3. Role of SHIP in B-cell negative signaling. Positive signals for B-cell growth and development are triggered by cross-linking the BCR and are shown in the right side. Resultant activation of $\mathrm{PI}^{\prime} \mathrm{K}$ produces the lipid $\mathrm{PI}(3,4,5) \mathrm{P} 3$, a high-affinity ligand for the $\mathrm{PH}$ domain of the tyrosine kinase Btk. The activation of Btk leads to cytolpasmic influx of $\mathrm{Ca}^{2+}$ from intracellular sources, ultimately resulting in growth and further B-cell development. The positive signal is attenuated greatly by the events shown within the gray-shaded area. Cross-linking the BCR to the FcyRIIB receptor at the cell surface begins the process that preempts the activation signal. The SHIP protein binds to a tyrosine-phosphorylated motif in the cytoplasmic sequence of the Fc $\gamma$ RIIB via its $\mathrm{SH} 2$ domain and converts $\mathrm{PI}(3,4,5) \mathrm{P} 3$ to $\mathrm{PI}(3,4) \mathrm{P} 2$ at the membrane activation sites. The loss of $\mathrm{PI}(3,4,5) \mathrm{P} 3$ is believed to prevent Btk activation; and thus, both intracellular $\mathrm{Ca}^{2+}$ influx and growth are attenuated.

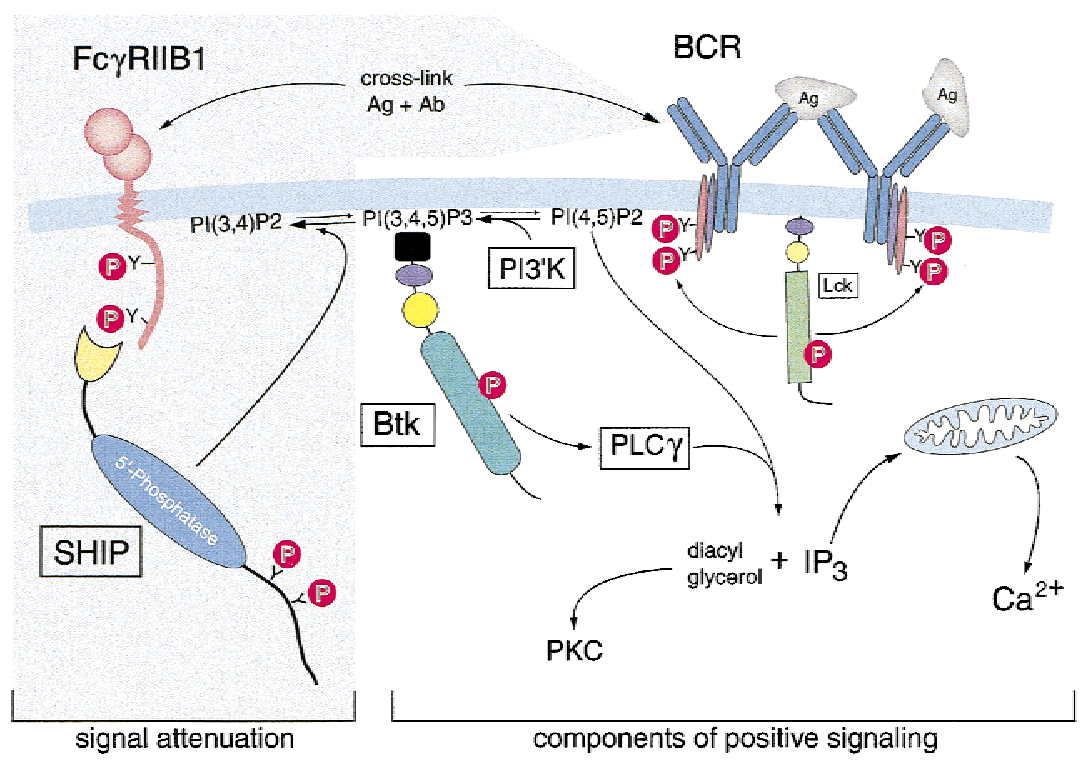


flux due to the SHIP 5'-phosphatase domain, plus additional negative activities are needed for a complete block in B-cell development. A good example of an additional negative signaling protein that may participate in this process is the Dok protein. Dok contributes to B cellnegative signaling but does not affect $\mathrm{Ca}^{2+}$ influx and therefore could contribute other negative functions (Yamanashi et al. 2000).

Myeloid cells (mast cells, neutrophils, macrophages, and their progenitors)

Mast cells provide an early line of defense against invading organisms or allergens. The release of a defensive mixture of molecules, stored in cytoplasmic granules, is triggered in these cells by immune complexes of monomeric IgE cross-linking the high-affinity cell-surface IgE receptor, Fc $\gamma$ RI. This receptor is comprised of three subunit proteins, two of which contain ITAM motifs in their short ( $<50$ amino acid) cytoplasmic tail. Like the Fc $\gamma$ RIIB1 receptor in B cells, the tyrosine-phosphorylated cytoplasmic region of the FceRI receptor on mast cells also binds the SH2 domain of SHIP upon aggregation (Osborne et al. 1996; Kimura et al. 1997). The mast cells undergo a large cytoplasmic $\mathrm{Ca}^{2+}$ influx, which presumably triggers, at least in part, the degranulation and release of defensive molecules. Mast cells, derived from $\mathrm{SHIP}^{+/+}$mouse bone marrow, exhibit the $\mathrm{Ca}^{2+}$ influx, whereas those derived from $S H I P^{-/-}$animals ehibit a more pronounced $\mathrm{Ca}^{2+}$ influx, especially subsequent to the initial spike of $\mathrm{Ca}^{2+}$ influx, suggesting a role of SHIP as the "gatekeeper" in setting the threshold for the overall signal (Huber et al. 1998). The exact mechanism for SHIP attenuation of the $\mathrm{Ca}^{2+}$ influx in mast cells has not been worked out, but aspects of the mechanism described for B cells might be presupposed.

In addition to the SHIP-regulated $\mathrm{Ca}^{2+}$ influx demonstrated in mast and B cells, other potential mechanisms of negative regulation have been described. The diagram in Figure 4A illustrates some of the interactions of SHIP within a generic myeloid cell. Cells from SHIP-null mice have been used to demonstrate the requirement for this protein in down-modulating a growth factor receptormediated Akt/PKB activation and survival signal in myeloid cells (Liu et al. 1999). IL-3 or GM-CSF stimulation of mast cells or neutrophils from $\mathrm{SHIP}^{+/+}$mice activates PI3'K producing $\mathrm{PI}(3,4,5) \mathrm{P} 3$. The $\mathrm{PH}$ domain of Akt/PKB interacts with the new phospholipids and becomes activated by phosphorylation at Ser-473 and Thr-308 in a PI $(3,4,5)$ P3-dependent manner. Subsequent phosphorylation of the Akt/PKB substrates occurs [ e.g., proapoptic signaling protein (BAD) and glycogen synthese kinase-3 (GSK-3)] and cell survival is extended. The PTEN protein (as discussed above) may regulate the basal levels of $\mathrm{PI}(3,4,5) \mathrm{P} 3$ (Myers et al. 1997). SHIP is proposed to regulate the growth factor induced levels of PI $(3,4,5) \mathrm{P} 3$, because mast cells from $\mathrm{SHIP}^{-/-}$animals exhibit greater Akt/PKB activation /measured by serine/threonine phosphoryaltion and GSK-3 phosphorylation), and it remains activated for extended times following IL-3 stimulation (Liu et al. 1999). SHIP ${ }^{-/-}$cells also exhibit an increased resistance to inducers of apoptosis, consistent with the role of Akt/PKB in this process. Additionally,
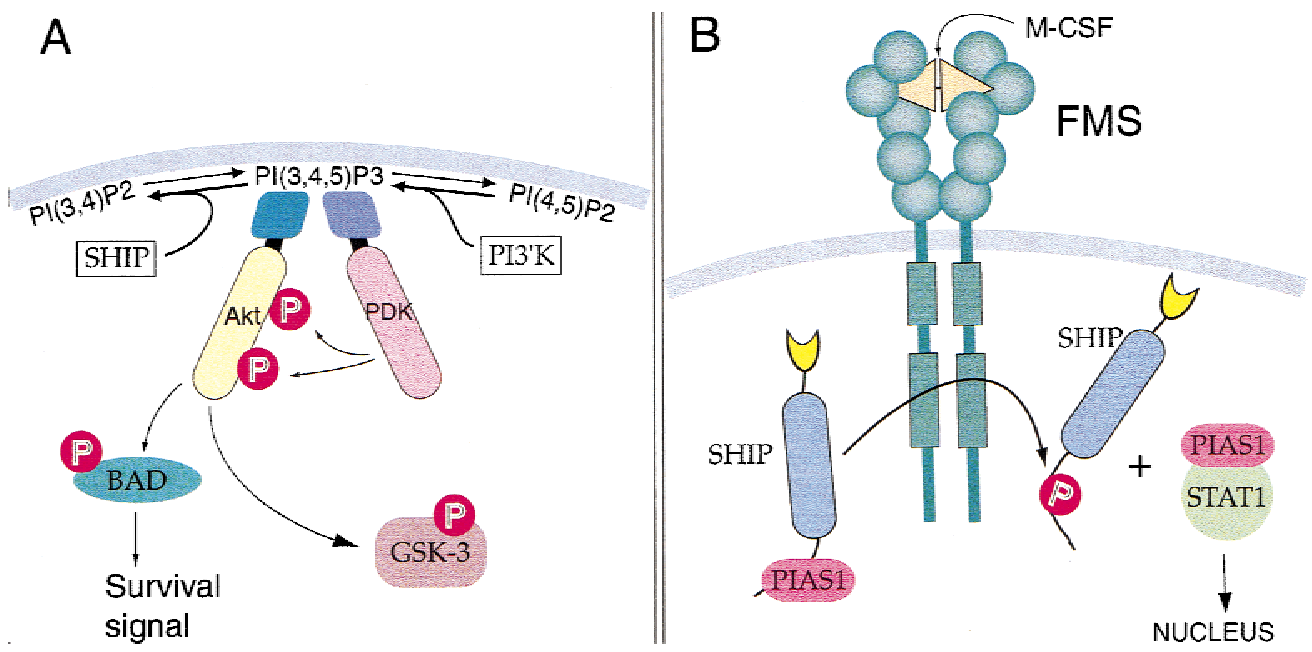

Figure 4. Negative regulation of cell growth and/or survival by SHIP may be achieved by different mechanisms. (A) Localized PI3'K activity, resulting from growth factor stimulation, produces the lipid $\mathrm{PI}(3,4,5) \mathrm{P} 3$, which serves as a binding site for the $\mathrm{PH}$ domains of the Akt/PKB kinase, as well as the PDK1 kinase, which activates Akt/PKB. The continued survival signal depends on activated Akt/PKB and the presence of the PI $(3,4,5) \mathrm{P} 3$ lipid at the membrane. SHIP ablates the positive survival signal by metabolizing the $\mathrm{PI}(3,4,5) \mathrm{P} 3$ to $\mathrm{PI}(3,4) \mathrm{P} 2$, a form that presumably is unable to support activation Akt/PBK. (B) An alternative mechanism for SHIP signaling is illustrated with the M-CSF receptor FMS. Activation of FMS by its ligand, M-CSF, results in tyrosine phosphorylation of several cytoplasmic proteins. SHIP becomes tyrosine phosphorylated by a yet unknown kinase, at one or both of the carboxy-terminal NPXY motifs. PIAS1 interacts with the carboxyl terminus of the unphosphorylated SHIP and is released from SHIP upon tyrosine phosphorylation. PIAS1 is known to interact with STAT1 and may modify STAT1 transcription following M-CSF stimulation. 
the $\mathrm{PI} 3^{\prime} \mathrm{K}$ inhibitor wortmannin prevents $\mathrm{PI}(3,4,5) \mathrm{P} 3$ accumulation and Akt/PKB activation, and sensitizes cells to apoptosis. These data indicate that PI3' $\mathrm{K}$ is essential for the resistance to apoptosis and Akt/PKB activation observed in $\mathrm{SHIP}^{+/+}$cells.

Phospholipids regulate Akt/PKB activation; however, this regulation is more complex than shown in Figure 4 because the $\mathrm{PH}$ domains of $\mathrm{Akt} / \mathrm{PKB}$ and $\mathrm{PDK} 1$ can interact with either $\mathrm{PI}(3,4,5) \mathrm{P} 3$ or $\mathrm{PI}(3,4) \mathrm{P} 2$ in the activation process (Stephens et al. 1998). Therefore, the overall mechanism becomes more complex than shown. Considering additional variables associated with phospholipid metabolism, there is definitely more to be learned about this step.

The complex nature of $\mathrm{PI}(3,4,5) \mathrm{P} 3$ in this overall process is also illustrated by the finding that in the B cell system, wortmannin also affected binding of the $\mathrm{PH}$ domain of Btk to this same lipid. SHIP also mediates the inhibition of Akt/PKB activation in B cells (Aman et al. 1998); therefore, activation of both Akt/PKB and Btk require binding to $\mathrm{PI}(3,4,5) \mathrm{P} 3$ via their $\mathrm{PH}$ domains.

A distinct mechanism for SHIP's negative role in cell growth and development may utilize proteins binding to the carboxy-terminal sequences of SHIP. In FDC-P1 cells expressing an exogenous M-CSF receptor (FMS), M-CSF stimulation recapitulates most features of macrophage differentiation (Rohrschneider and Metcalf 1989). SHIP participates in the FMS signaling, and as described above, the PIAS1 protein was found to bind constitutively to the carboxyl terminus of SHIP in unstimulated cells. Interestingly, M-CSF stimulation resulted in SHIP tyrosine phosphorylation and decreased interaction between SHIP and PIAS1. The fate of PIAS1 in this system is not yet clear, but its specific interaction with activated STAT1 (B. Liu et al. 1998) suggests a role in transcriptional regulation. STAT1 is necessary for transcriptional activation of genes mediating innate immunity to viral disease (Durbin et al. 1996), and PIAS1 might modify that response. Thus, whereas the functions of SHIP described in Figures 3 and $4 \mathrm{~A}$ rely primarily on the $5^{\prime}$ phosphatase enzymatic domain, the activity diagramed in Figure 4B depends on effector proteins attached to SHIP. The role of effector proteins in SHIP function has not been thoroughly explored but should provide additional clues for understanding the mechanisms of SHIP's negative functions.

\section{Role of SHIP in human disease}

Research on potential physiological roles of SHIP proteins in human maladies has, so far, yielded no direct connection with tumor suppression or tumor formation, as measured by over expression studies, mutational analysis, or examination of the SHIP chromosomal abnormalities associated with disease states. Results from the SHIP knockout studies in mice largely agree that SHIP deficiency in the blood cells results in myeloproliferation and hyper-responsiveness to growth factor stimulation. A similar spectrum of abnormalities is seen in $B C R-A B L$-induced transformation of mice, and Sattler et al. (1999) have exploited this relationship to show that $B C R-A B L$, a causative oncogene for chronic myelogenous leukemia (CML) in both humans and mice, inhibits expression of the SHIP protein. The kinase activity of BCR-ABL is necessary for the SHIP suppression because a chemical inhibitor of the ABL kinase activity restored SHIP expression. This same inhibitor (Novartis, CGP57148B) has now undergone clinical trials in humans, and the results indicate successful drug therapy against CML (B. Druker, pers. comm.). Although the role of SHIP in the CML drug therapy trial was not examined, these results raise the possibility of a more fundamental role for SHIP in regulating the preleukemic stages of disease formation. Examination of potential roles of SHIP in related disease states of blood cell formation may be worthwhile. Such disease states would include myeloproliferative disorders, polycythemia vera, agnogenic myeloid metaplasia, primary thrombocythemia, and chronic monocytic or neutrophilic leukemias.

\section{Acknowledgments}

This review represents the collective thinking of our laboratory; therefore, we apologize for omitting any alternative references or views. We greatly appreciate the comments, suggestions, and help from reviewers and numerous colleagues, as well as permission from Dr. Brian Druker to use clinical trial results before publication. Research in our laboratory was supported by the Fred Hutchinson Center and grants from the National Cancer Institute (CA20551 and CA4987). D.M.L. was supported in part by an NRSA fellowship (DK09774), and J.E.F. was supported by a training grant from the University of Washington (CA09437).

\section{References}

Aman, M.J., T.D. Lamkin, H. Okada, T. Kurosaki, and K.S. Ravichandran. 1998. The inositol phosphatase SHIP inhibits Akt/PKB activation in B cells. J. Biol. Chem. 273: 3392233928.

Attree, O., I.M. Olivos, I. Okabe, L.C. Bailey, D.L. Nelson, R.A. Lewis, R.R. McInnes, and R.L. Nussbaum. 1992. The Lowe's oculocerebrorenal syndrome gene encodes a protein highly homologous to inositol polyphosphate-5-phosphatase. $\mathrm{Na}$ ture 358: 239-242.

Bolland, S., R.N. Pearse, T. Kurosaki, and J.V. Ravetch. 1998. SHIP modulates immune receptor responses by regulating membrane association of Btk. Immunity 8: 509-516.

Bruyns, C., X. Pesesse, C. Moreau, D. Blero, and C. Erneux. 1999. The two SH2-domain-containing inositol 5-phosphatases SHIP1 and SHIP2 are coexpressed in human T lymphocytes. Biol. Chem. 380: 969-974.

Carlberg, K. and L.R. Rohrschneider. 1997. Characterization of a novel tyrosine phosphorylated $100 \mathrm{kDa}$ protein that binds to SHP-2 and phosphatidylinositol 3'-kinase in hematopoietic cells. J. Biol. Chem. 272: 15943-15950.

Chacko, G.W., S. Tridandapani, J.E. Damen, L. Liu, G. Krystal, and K.M. Coggeshall. 1996. Negative signaling in B lymphocytes induces tyrosine phosphorylation of the $145-\mathrm{kDa}$ inositol polyphosphate 5-phosphatase, SHIP. I. Immunol. 157: 2234-2238.

Chung, C.D., J. Liao, B. Liu, X. Rao, P. Jay, P. Berta, and K. Shuai. 
1997a. Specific inhibition of Stat3 signal transduction by PIAS3. Science 278: 1803-1805.

Chung, J.K., F. Sekiya, H.S. Kang, C. Lee, J.S. Han, S.R. Kim, Y.S. Bae, A.J. Morris, and S.G. Rhee. 1997b. Synaptojanin inhibition of phospholipase D activity by hydrolysis of phosphatidylinositol 4,5-bisphosphate. J. Biol. Chem. 272: 1598015985.

Coggeshall, K.M. 1998. Inhibitory signaling by B cell FcgRIIb. Curr. Opin. Immunol.10: 306-312.

Conley, M.E. and J. Rohrer. 1995. The spectrum of mutations in Btk that cause X-linked agammaglobulinemia. Clin. Immunol. Immunopathol. 76: S192-S197.

Cremona, O., G. Di Paolo, M.R. Wenk, A. Luthi, W.T. Kim, K. Takei, L. Daniell, Y. Nemoto, S.B. Shears, R.A. Flavell et al. 1999. Essential role of phosphoinositide metabolism in synaptic vesicle recycling. Cell 99: 179-188.

Crowley, M.T., S.L. Harmer, and A.L. DeFranco. 1996. Activation-induced association of a $145-\mathrm{kDa}$ tyrosine-phosphorylated protein with Shc and Syk in B lymphocytes and macrophages. J. Biol. Chem. 271: 1145-1152.

Damen, J.E., L. Liu, R.L. Cutler, and G. Krystal. 1993. Erythropoietin stimulates the tyrosine phosphorylation of Shc and its association with Grb2 and a 145-Kd tyrosine phosphorylated protein. Blood 82: 2296-2303.

Damen, J.E., L. Liu, P. Rosten, R.K. Humphries, A.B. Jefferson, P.W. Majerus, and G. Krystal. 1996. The 145-kDa protein induced to associate with Shc by multiple cytokines is an inositol tetraphosphate and phosphatidylinositol 3,4,5-trisphosphate 5-phosphatase. Proc. Natl. Acad. Sci. 93: 16891693.

Damen, J.E., L. Liu, M.D. Ware, M. Ermolaeva, P.W. Majerus, and G. Krystal. 1998. Multiple forms of the SH2-containing inositol phosphatase, SHIP, are generated by C-terminal truncation. Blood 92: 1199-1205.

Deuter-Reinhard, M., G. Apell, D. Pot, A. Klippel, L.T. Williams, and W.M. Kavanaugh. 1997. SIP/SHIP inhibits Xenopus oocyte maturation induced by insulin and phosphatidylinositol 3-kinase. Mol. Cell. Biol. 17: 2559-2565.

Di Cristofano, A., B. Pesce, C. Cardon-Cardo, and P.P. Pandolfi. 1998. Pten is essential for embryonic development and tumour suppression. Nat. Genet. 19: 348-355.

Drachman, J.G., J.D. Griffin, and K. Kaushansky. 1995. The c$\mathrm{Mpl}$ ligand (thrombopoietin) stimulates tyrosine phosphorylation of Jak2, Shc, and c-Mpl. J. Biol. Chem. 270: 49794982.

Drayer, A.L., X. Pesesse, F. De Smedt, R. Woscholski, P. Parker, and C. Erneux. 1996. Cloning and expression of a human placenta inositol 1,3,4,5-tetrakisphosphate and phosphatidylinositol 3,4,5-trisphosphate 5-phosphatase. Biochem. Biophys. Res. Common. 225: 243-249.

Durbin, J.E., R. Hackenmiller, M.C. Simon, and D.E. Levy. 1996. Targeted disruption of the mouse Stat1 gene results in compromised innate immunity to viral disease. Cell 84: 443-450.

Fauman, E.B. and M.A. Saper. 1996. Structure and function of the protein tyrosine phosphatases. Trends Biochem. Sci. 21: 413-417.

Felder, S., M. Zhou, P. Hu, J. Ureña, A. Ullrich, M. Chaudhuri, M. White, S.E. Shoelson, and J. Schlessinger. 1993. SH2 domains exhibit high-affinity binding to tyrosine-phosphorylated peptides yet also exhibit rapid dissociation and exchange. Mol. Cell. Biol. 13: 1449-1455.

Fluckiger, A.-C., Z. Li, R.M. Kato, M.I. Wahl, H.D. Ochs, R. Longnecker, J.-P. Kinet, O.N. Witte, A.M. Scharenberg, and D.J. Rawlings. 1998. Btk/Tec kinases regulate sustained increases in intracellular $\mathrm{Ca}^{2+}$ following $\mathrm{B}$-cell receptor acti- vation. EMBO J. 17: 1973-1985.

Fukuda, M., T. Kojima, H. Kabayama, and K. Mikoshiba. 1996. Mutation of the pleckstrin homology domain of Bruton's tyrosine kinase in immunodeficiency impaired inositol 1,3,4,5-tetrakisphosphate binding capacity. J. Biol. Chem. 271: 30303-30306.

Geier, S.J., P.A. Algate, K. Carlberg, D. Flowers, C. Friedman, B. Trask, and L.R. Rohrschneider. 1997. The human SHIP gene is differentially expressed in cell lineages of the bone marrow and blood. Blood 89: 1876-1885.

Giuriato, S., B. Payrastre, A.L. Drayer, M. Plantavid, R. Woscholski, P. Parker, C. Erneux, and H. Chap. 1997. Tyrosine phosphorylation and relocation of SHIP are integrin-mediated in thrombin-stimulated human blood platelets. J. Biol. Chem. 272: 26857-26863.

Gu, H., J.C. Pratt, S.J. Burakoff, and B.G. Neel. 1998. Cloning of p97/Gab2, the major SHP2-binding protein in hematopoietic cells, reveals a novel pathway for cytokine-induced gene activation. Mol. Cell 2: 729-740.

Guilherme, A., J.K. Klarlund, G. Krystal, and M.P. Czech. 1996. Regulation of phosphatidylinositol 3,4,5-trisphosphate 5'phosphatase activity by insulin. J. Biol. Chem. 271: 2953329536.

Gupta, N., A.M. Scharenberg, D.N. Burshtyn, M.N. Lioubin, L.R. Rohrschneider, J.-P. Kinet, and E.O. Long. 1997. Negative signaling pathways of killer cell inhibitory receptors and Fc $\gamma$ RIIb1 require distinct phosphatases. J. Exp. Med. 186: 473-478.

Gupta, N., A.M. Scharenberg, D.A. Fruman, L.C. Cantley, J.-P. Kinet, and E.O. Long. 1999. The SH2 domain-containing inositol 5'-phosphatase (SHIP) recruits the p85 subunit of phosphoinositide 3-kinase during Fc $\gamma$ RIIb1-mediated inhibition of B cell receptor signaling. J. Biol. Chem. 274: 7489-7494.

Harmer, S.L. and A.L. DeFranco. 1999. The src homology domain 2-containing inositol phosphatase SHIP forms a ternary complex with Shc and Grb2 in antigen receptor-stimulated B lymphocytes. J. Biol. Chem. 274: 12183-12191.

Hejna, J.A., H. Saito, L.S. Merkens, T.V. Tittle, P.M. Jakobs, M.A. Whitney, M. Grompe, A.S. Friedberg, and R.E. Moses. 1995. Cloning and characterization of a human cDNA (INPPL1) sharing homology with inositol polyphosphate phosphatases. Genomics 29: 285-287.

Helgason, C.D., J.E. Damen, P. Rosten, R. Grewal, P. Sorenson, S.M. Chappel, A. Borowski, F. Jirik, G. Krystal, and R.K. Humphries. 1998. Targeted disruption of SHIP leads to hemopoietic perturbations, lung pathology, and a shortened life span. Genes \& Dev. 12: 1610-1620.

Hippen, K.L., A.M. Buhl, D. D'Ambrosio, K. Nakamura, C. Persin, and J.C. Cambier. 1997. FcyRIIb11 inhibtion of BCR mediated phosphoinositide hydrolysis and $\mathrm{Ca}^{2+}$ mobilization is integrated by CD19 dephosphorylation. Immunity 7: 49-58.

Holgado-Madruga, M., D.R. Emlet, D.K. Moscatello, A.K. Godwin, and A.J. Wong. 1996. A Grb2-associated docking protein in EGF- and insulin-receptor signalling. Nature 379: 560-564.

Howell, B.W., L.M. Lanier, R. Frank, F.B. Gertler, and J.A. Cooper. 1999. The disabled 1 phosphotyrosine-binding domain binds to the internalization signals of transmembrane glycoproteins and to phospholipids. Mol. Cell. Biol. 19: 51795188.

Huber, M., C.D. Helgason, J.E. Damen, L. Liu, R.K. Humphries, and G. Krystal. 1998. The src homology 2-containing inositol phosphatase (SHIP) is the gatekeeper pf mast cell degranulation. Proc. Nat1. Acad. Sci. 95: 11330-11335.

Huber, M., C.D. Helgason, J.E. Damen, M.P. Scheid, V. Duronio, 
V. Lam, R.K. Humphries, and G. Krystal. 1999. The role of the SRC homology 2-containing insitol 5'-phosphatase in Fc epsilon R1-induced signaling. Curr. Top. Microbiol. Immunol. 244: 29-41.

Huyer, G. and D.R. Alexander.1999. Immune signalling: SHP-2 docks at multiple ports. Curr. Biol. 9: R129-R132.

Ingham, R.J., H. Okada, M. Dang-Lawson, J. Dinglasan, and P. van der Geer. 1999. Tyrosine phosporylation of She in response to B cell antigen receptor engagement depends on the SHIP inositol phosphatase. J. Immunol. 163: 5891-5895.

Kavanaugh, W.M. and L.T. Williams. 1994. An alternative to SH2 domains for binding tyrosine-phosphorylated proteins. Science 266: 1862-1865.

Kavanaugh, W.M., D.A. Pot, S.M. Chin, M. Deuter-Reinhard, A.B. Jefferson, F.A. Norris, F.R. Masiarz, L.S. Cousens, P.W. Majerus, and L.T. Williams. 1996. Multiple forms of an inositol polyphosphate 5-phosphatase form signaling complexes with Shc and Grb2. Curr. Biol. 6: 438-445.

Kawano, T., Y. Indo, H. Nakazato, M. Shimadzu, and I. Matsuda. 1998. Oculocerebrorenal syndrome of Lowe: Three mutations in the OCRL1 gene derived from three patients with different phenotypes. Am. J. Med. Genet. 77: 348-355.

Khvotchev, M. and T.C. Südhof. 1998. Developmentally regulated alternative splicing in a novel synaptojanin. J. Biol. Chem. 273: 2306-2311.

Kiener, P.A., M.N. Lioubin, L.R. Rohrschneider, J.A. Ledbetter, S.G. Nadler, and M.L. Diegel. 1997. Co-ligation of the antigen and Fc receptors gives rise to the selective modulation of intracellular signaling in B cells. J. Biol. Chem. 272: 3838 3844.

Kimura, T., H. Sakamoto, E. Appella, and R. P. Siraganian. 1997. The negative signaling molecule SH2 domain-containing inositol-polyphosphate 5-phosphatase (SHIP) binds to the tyrosine-phosphorylated beta subunit of the high affinity $\operatorname{IgE}$ receptor. J. Biol. Chem. 272: 13991-13996.

Kuroiwa, A., Y. Yamashita, M. Inui, T. Yuasa, M. Ono, A. Nagabukuro, Y. Matsuda, and T. Takai. 1998. Association of tyrosine phosphatases SHP-1 and SHP-2, inositol 5-phosphatase SHIP with gp49B1, and chromosomal assignment of the gene. J. Biol. Chem. 273: 1070-1074.

Kurosaki, T. 1999. Genetic analysis of B cell antigen receptor signaling. Annu. Rev. Immunol. 17: 555-592.

Lamkin, T.D., S.F. Walk, L. Liu, J.E. Damen, G. Krystal, and K.S. Ravichandran. 1997. She interaction with Src homology 2 domain containing isositol phosphatase (SHIP) in vivo requires the Shc-phosphotyrosine binding domain and two specific phosphotyrosines on SHIP. I. Biol. Chem. 272: 10396-10401.

Lecoq-Lafon, C., F. Verdier, S. Fichelson, S. Chrétien, S. Gisselbrecht, C. Lacombe, and P. Mayeux. 1999. Erythropoietin induces the tyrosine phosphorylation of GAB1 and its association with SHC, SHP2, SHIP, and phosphatidylinositol 3-kinase. Blood 93: 2578-2585.

Lewis, T.S., P.S. Shapiro, and N.G. Ahn. 1998. Signal transduction through MAPK cascades. Adv. Cancer Res. 74: 49-139.

Li, J., C. Yen, D. Liaw, K. Podsypanina, S. Bose, S.I. Wang, J. Puc, C. Miliaresis, L. Rodgers, R. McCombie et al. 1997. PTEN, a putative protein tyrosine phosphatase gene mutated in human brain, breast, and prostate cancer. Science 275: 19431947.

Lioubin, M.N., G.M. Myles, K. Carlberg, D. Bowtell, and L.R. Rohrschneider. 1994. SHC, GRB2, SOS1 and a 150-kilodalton tyrosine-phosphorylated protein form complexes with Fms in hematopoietic cells. Mol. Cell. Biol. 14: 5682-5691.

Lioubin, M.N., P.A. Algate, S. Tsai, K. Carlberg, R. Aebersold, and L.R. Rohrschneider. 1996. p150 ${ }^{\text {Ship }}$, a signal transduction molecule with inositol polyphosphate-5-phosphatase activity. Genes \& Dev. 10: 1084-1095.

Liu, B., J. Liao, X. Rao, S.A. Kushner, C.D. Chung, D.D. Chang, and K. Shuai. 1998. Inhibition of Stat1-mediated gene activation by PIAS1. Proc. Nat1. Acad. Sci. 95: 10626-10631.

Liu, L., J.E. Damen, R.L. Cutler, and G. Krystal. 1994. Multiple cytokines stimulate the binding of a common 145-kilodalton protein to Shc at the Grb2 recognition site of Shc. Mol. Cell. Biol. 14: 6926-6935.

Liu, L., J.E. Damen, M.R. Hughes, I. Babic, F.R. Jirik, and G. Krystal. 1997a. The Src homology 2 (SH2) domain of SH2containing inositol phosphatase (SHIP) is essential for tyrosine phosphorylation of SHIP, its association with Shc, and its induction of apoptosis. J. Biol. Chem. 272: 8983-8988.

Liu, L., J. E. Damen, M.D. Ware, and G. Krystal. 1997b. Interleuken-3 induces the association of the inositol 5-phosphatase SHIP with SHP2. J. Biol. Chem. 272: 10998-11001.

Liu, Q., Amgen E.S.T. Program, and D.J. Dumont. 1997. Molecular cloning and chromosomal localization in human and mouse of the SH2-containing inositol phosphatase, INPP5D (SHIP). Genomics 39: 109-112.

Liu, Q., F. Shalaby, J. Jones, D. Bouchard, and D.J. Dumont. 1998. The SH2-containing inositol polyphosphate 5-phosphatase, Ship, is expressed during hematopoiesis and spermatogenesis. Blood 91: 2753-2759.

Liu, Q., T. Sasaki, I. Kozieradzki, A. Wakeham, A. Itie, D.J. Dumont, and J.M. Penninger. 1999. SHIP is a negative regulator of growth factor receptor-mediated PKB/Akt activation and myeloid cell survival. Genes \& Dev. 13: 786-791.

Lucas, D.M. and L.R. Rohrschneider. 1999. A novel spliced form of SH2-containing inositol phosphatase SHIP is expressed during myeloid development. Blood 93: 1922-1933.

Maehama, T. and J.E. Dixon. 1999. PTEN: A tumour suppressor that functions as a phospholid phosphatase. Trends Cell Biol. 9: 125-128.

Majerus, P.W., M.V. Kisseleva, and F.A. Norris. 1999. The role of phosphatases in inositol signaling reactions. J. Biol. Chem. 274: 10669-10672.

Maresco, D.L., J.M. Osborne, D. Cooney, K.M. Coggeshall, and C.L. Anderson. 1999. The SH2-containing 5'-inositol phosphatase (SHIP) is tyrosine phosphorylated after Fc gamma receptor clustering in monocytes. J. Immunol. 162: 64586465.

Matsuguchi, T., R. Salgia, M. Hallek, M. Eder, B. Druker, T.J. Ernst, and J.D. Griffin. 1994. Shc Phosphorylation in myeloid cells is regulated by granulocyte macrophage colonystimulating factor, Interleukin-3, and steel factor is constitutively increased by $\mathrm{p} 210^{\mathrm{BCR} / \mathrm{ABL}}$. J. Biol. Chem. 269: $5016-$ 5021.

McPherson, P.S., E.P. Garcia, V.I. Slepnev, C. David, X. Zhang, D. Grabs, W.S. Sossin, R. Bauerfeind, Y. Nemeto, and P. De Camilli. 1996. A presynaptic inositol-5-phosphatase. Nature 379: 353-357.

Myers, M.P., J.P. Stolarov, C. Eng, J. Li, S.I. Wang, M.H. Wigler, R. Parsons, and N.K. Tonks. 1997. PTEN, the tumor suppressor from human chromosome 10q23, is a dual-specificity phosphatase. Proc. Natl. Acad. Sci. 94: 9052-9057.

Nemoto, Y. and P. De Camilli. 1999. Recruitment of an alternatively spliced form of synaptojanin 2 to mitochondria by the interaction with the PDZ domain of a mitochondrial outer membrane protein. EMBO J. 18: 2991-3006.

Nemoto, Y., M. Arribas, C. Haffner, and P. De Camilli. 1997. Synaptojanin 2, a novel synaptojanin isoform with a distinct targeting domain and expression pattern. I. Biol. Chem. 272: 30817-30821.

Nishida, K., Y. Yoshida, M. Itoh, T. Fukada, T. Ohtani, T. Shi- 
rogane, T. Atsumi, M. Takahashi-Tezuka, K. Ishihara, M. Hibi, and T. Hirano. 1999. Gab-family adapter proteins act downstream of cytokine and growth factor receptors and Tand B-cell antigen receptors. Blood 93: 1809-1816.

Norris, F., V. Auethavekiat and P.W. Majerus. 1995. The isolation and characterization of cDNA encoding human and rat brain inositol polyphosphate 4-phosphatase. J. Biol. Chem. 270: 16128-16133.

Norris, F.A., R.C. Atkins, and P.W. Majerus. 1997. Inositol polyphosphate 4-phosphatase is inactivated by Calpain-mediated ptoteolysis in stimulated human platelets. J. Biol. Chem. 272: 10987-10989.

Odai, H., K. Sasaki, A. Iwamatsu, T. Nakamoto, H. Ueno, T. Yamagata, K. Mitani, Y. Yazaki, and H. Hirai. 1997. Purification and molecular cloning of SH2- and SH3-containing inositol polyphosphate-5-phosphatase, which is involved in the signaling pathway of granulocyte-macrophage colonystimulating factor, erythropoietin, and Bcr-Abl. Blood 89: $2745-2756$.

Okada, H., S. Bolland, A. Hashimoto, M. Kurosaki, Y. Kabuyama, M. Iino, J.V. Ravetch and T. Kurosaki. 1998. Cutting edge: Role of the inositol phosphatase SHIP in B cell receptor-induced $\mathrm{Ca}^{2+}$ oscillatory response. I. Immunol. 161: 5129-5132.

Ono, M., S. Bolland, P. Tempst, and J. . Ravetch. 1996. Role of the inositol phosphatase SHIP in negative regulation of the immune system by the receptor Fc $\gamma$ RIIB. Nature 383: 263 266.

Ono, M., H. Okada, S. Bolland, S. Yanagi, T. Kurosaki, and J.V. Ravetch. 1997. Deletion of SHIP or SHP-1 reveals two distinct pathways for inhibitory signaling. Cell 90: 293-301.

Osborne, M.A., G. Zenner, M. Lubinus, X. Zhang, Z. Songyang, L.C. Cantley, P. Majerus, P. Burn, and J.P. Kochan. 1996. The inositol 5'-phosphatase SHIP binds to immunoreceptor signaling motifs and responds to high affinity IgE receptor aggregation. J. Biol. Chem. 271: 29271-29278.

Pesesse, X., S. Deleu, F. De Smedt, L. Drayer, and C. Erneux. 1997. Identification of a second SH2-domain-containing protein closely related to the phosphatidylinositol polyphosphate 5-phosphatase SHIP. Biochem. Biophys. Res. Comm. 239: 697-700.

Podsypanina, K., L.H. Ellenson, A. Nemes, J. Gu, M. Tamura, K.M. Yamada, C. Cordon-Cardo, G. Catoretti, P.E. Fisher, and R. Parsons. 1999. Mutation of Pten/Mmac1 in mice causes neoplasia in multiple organ systems. Proc. Natl. Acad. Sci. 96: 1563-1568.

Pradhan, M. and K. M. Coggeshall. 1997. Activation-induced bi-dentate interaction of SHIP and Shc in B lymphocytes. J. Cell. Biochem. 67: 32-42.

Rameh, L.E., A.K. Arvidsson, K.L. Carraway III, A.D. Couvillon, G. Rathbun, A. Crompton, B. VanRenterghem, M.P. Czech, K.S. Ravichandran, S.J. Burakoff et al. 1997. A comparative analysis of the phosphoinositide binding specificity of pleckstrin homology domains. J. Biol. Chem. 272: 22059-22066.

Rawlings, D.J. and O.N. Witte. 1994. Bruton's tyrosine kinase is a key regulator in B cell development. Immunol. Rev. 138: $105-119$.

- 1995. The Btk subfamily of cytoplasmic tyrosine kinases: Structure, regulation, and function. Semin. Immunol. 7: 237-246.

Rohrschneider, L.R. and D. Metcalf. 1989. Induction of macrophage colony stimulating factor-dependent growth and differentiation after introduction of the murine c-fms gene into FDC-P1 cells. Mol. Cell. Biol. 9: 5081-5092.

Rozakis-Adcock, M., J. McGlade, G. Mbamula, G. Pelicci, R. Daly, W. Li, A. Batzer, S. Thomas, J. Brugge, P. G. Pelicci et al. 1992. Association of the Shc and Grb2/Sem5 SH2-containing proteins is implicated in activation of the Ras pathway by tyrosine kinases. Nature 360: 689-692.

Saito, T. 1998. Negative regulation of T cell activation. Curr. Opin. Immunol. 10: 313-321.

Salim, K., M.J. Bottomley, E. Querfurth, M.J. Zvelebil, I. Gout, R. Scaife, R.L. Margolis, R. Gigg, C.I.E. Smith, P.C. Driscoll et al. 1996. Distinct specificity in the recognition of phosphoinositides by the pleckstrin homology domains of dynamin and Bruton's tyrosine kinase. EMBO J. 15: 6241-6250.

Sattler, M., R. Salgia, G. Shrikhande, S. Verma, J.-L. Choi, L.R. Rohrschneider, and J.D. Griffin. 1997. The phosphatidylinositol polyphosphate 5-phosphatase SHIP and the protein tyrosine phosphatase SHP2 form a complex in hematopoietic cells which can be regulated by $\mathrm{BCR} / \mathrm{ABL}$ and growth factors. Oncogene 15: 2379-2384.

Sattler, M., S. Verma, C.H. Byrne, G. Shrikhande, T. Winkler, P.A. Algate, L.R. Rohrschneider, and J.D. Griffin. 1999. BCR/ABL directly inhibits expression of SHIP, an SH2-containing polyinositol-5-phosphatase involved in the regulation of hematopoiesis. Mol. Cell. Biol. 19: 7473-7480.

Saxton, T.M., I. van Oostveen, D. Bowtell, R. Aebersold, and M.R. Gold. 1994. B cell antigen receptor cross-linking induces phosphorylation of the p21iras oncoprotein activators SHC and mSOS1 as well as assembly of complexes containing SHC, GRB-2, mSOS1, and a $145-\mathrm{kDa}$ tyrosine-phosphorylated protein. I. Immunol. 153: 623-636.

Schaffhausen, B. 1995. SH2 domain structure and function. Biochim. Biophys. Acta 1242: 61-75.

Scharenberg, A.M., O. El-Hillal, D.A. Fruman, L.O. Beitz, Z. Li, S. Lin, I. Gout, L.C. Cantley, D.J. Rawlings, and J.-P. Kinet. 1998. Phosphatidylinositol-3,4,5-trisphosphate (Ptdlns3,4,5- $\left.\mathrm{P}_{3}\right) /$ Tec kinase-dependent calcium signaling pathway: A target for SHIP-mediated inhibitory signals. EMBO $\mathrm{T}$. 17: 1961-1972.

Seet, L.F., S. Cho, A. Hessel, and D.J. Dumont. 1998. Molecular cloning of multiple isoforms of synaptojanin 2 and assignment of the gene to mouse chromosome 17A2-3.1. Biochem. Biophys. Res. Comm. 247: 116-122.

Songyang, Z., S.E. Shoelson, M. Chaudhuri, G. Gish, T. Pawson, W.G. Haser, F. King, T. Roberts, S. Ratnofsky, R.J. Lechleider et al. 1993. SH2 domains recognize specific phosphopeptide sequences. Cell 72: 767-778.

Steck, P.A., M.A. Pershouse, S.A. Jasser, W.K.A. Yung, H. Lin, A.H. Ligon, L.A. Langford, M.L. Baumgard, T. Hattier, T. Davis et al. 1997. Identification of a candidate tumor suppressor gene, MMAC1, at chromosome 10q23.3 that is mutated in multiple advanced cancers. Nat. Genet. 15:356362.

Stephens, L., K. Anderson, D. Stokoe, H. Erdjument-Bromage, G.F. Painter, A.B. Holmes, P.R.J. Gaffney, C.B. Reese, F. McCormick, P. Tempst et al. 1998. Protein kinase B kinases that mediate phosphatidylinositol 3,4,5-trisphosphate-dependent activation of protein kinase B. Science 279: 710715.

Suzuki, A., J.L. de la Pompa, V. Stambolic, A.J. Elia, T. Sasaki, I.d.B. Barrantes, A. Ho, A. Wakeham, A. Itie, W. Khoo et al. 1998. High cancer susceptibility and embryonic lethality associated with mutation of the PTEN tumor suppressor gene in mice. Curr. Biol. 8: 1169-1178.

Tridandapani, S., G.W. Chacko, J.R. Van Brocklyn, and K.M. Coggeshall. 1997. Negative signalling in B cells causes reduced Ras activity by reducing Shc-Grb2 interactions. J. Immunol. 158: 1125-1132.

Tridandapani, S., M. Pradhan, J.R. LaDine, S. Garber, C.L. Anderson, and K.M. Coggeshall. 1999. Protein interactions 


\section{Rohrschneider et al.}

of Src homology 2 (SH2) domain-containing inositol phosphatase (SHIP): Association with Shc displaces SHIP from Fc $\gamma$ RIIb in B cells. J. Immunol. 162: 1408-1414.

Unkeless, J.C. and J. Jin. 1997. Inhibitory receptors, ITIM sequences and phospatases. Curr. Opin. Immunol. 9: 338-343.

van der Geer, P. and T. Pawson. 1995. The PTB domain: A new protein module implicated in signal transduction. Trends Biochem. Sci. 20: 277-280.

Vély, F., S. Olivero, L. Olcese, A. Moretta, J.E. Damen, L. Liu, G. Krystal, J.C. Cambier, M. Daëron, and E. Vivier. 1997. Differential association of phosphatases with hematopoietic coreceptors bearing immunoreceptor tyrosine-based inhibition motifs. Eur. J. Immunol. 27: 1994-2000.

Ware, M.D., P. Rosten, J.E. Damen, L. Liu, K. Humphries, and G. Krystal. 1996. Cloning and characterization of human SHIP, the $145-\mathrm{kD}$ inositol 5-phosphatase that associates with SHC after cytokine stimulation. Blood 88: 2833-2840.

Wisniewski, D., A. Strife, S. Swendeman, H. Erdjument-Bromage, S. Geromanos, W.M. Kavanaugh, P. Tempst, and B. Clarkson. 1999. A novel SH2-containing phosphatidylinositol 3,4,5-trisphosphate 5-phosphatase (SHIP2) is constitutively tyrosine phosphorylated and associated with src homologous and collagen gene (SHC) in chronic myelogenous leukemia progenitor cells. Blood 93: 2707-2720.

Yamanashi, Y., T. Tamura, T. Kanamori, H. Yamane, H. Nariuchi, T. Yamamoto, and D. Baltimore. 2000. Role of the rasGAP-associated docking protein $\mathrm{p} 62^{\text {dok }}$ in negative regulation of B cell receptor-mediated signaling. Genes \& Dev. 14: $11-16$.

Zhang, Z.-Y., Y. Wang, E.B. Fauman, J.A. Stuckey, H.L. Schubert, M.A. Saper, and J.E. Dixon. 1994. The Cys $(\mathrm{X})_{5}$ Arg catalytic motif in phosphoester hydrolysis. Biochemistry 33: $15266-15270$.

Zhou, G., J.M. Denu, and J.E. Dixon. 1994. The catalytic role of Cyst $^{124}$ in the dual specificity phosphatase VHR. I. Biol. Chem. 269: 28084-28090. 


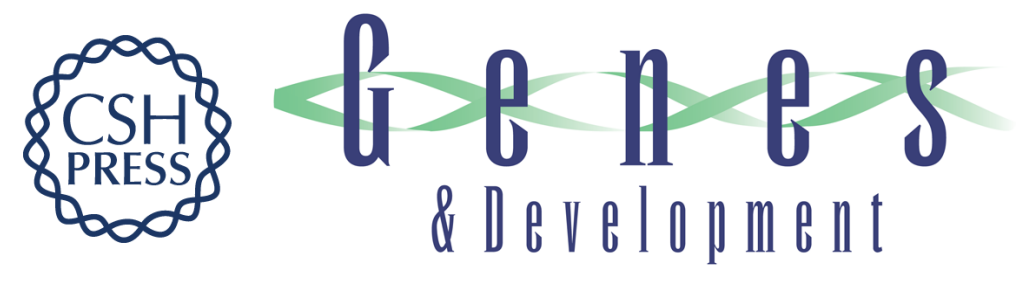

\section{Structure, function, and biology of SHIP proteins}

Larry R. Rohrschneider, John F. Fuller, Ingrid Wolf, et al.

Genes Dev. 2000, 14:

Access the most recent version at doi:10.1101/gad.14.5.505

References This article cites 108 articles, 66 of which can be accessed free at: http://genesdev.cshlp.org/content/14/5/505.full.html\#ref-list-1

License

Email Alerting Receive free email alerts when new articles cite this article - sign up in the box at the top Service right corner of the article or click here.

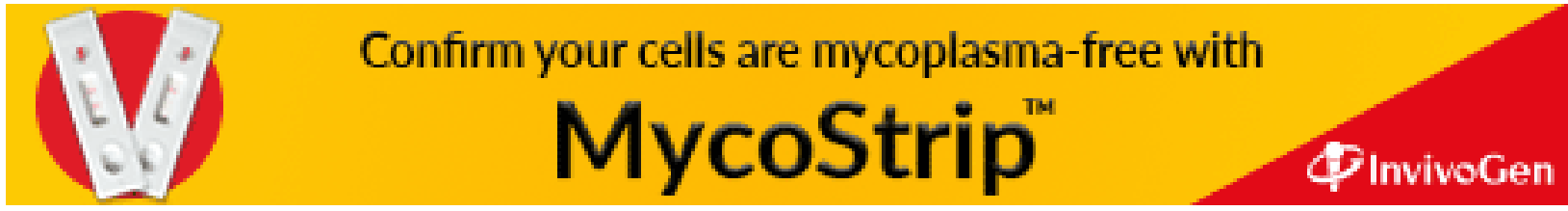

